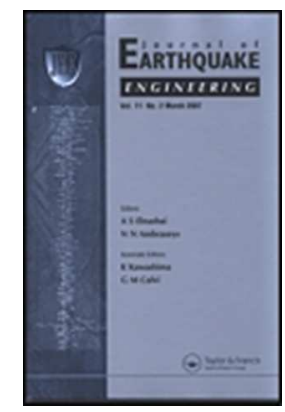

\title{
Pushover analyses of steel storage shelving racks
}

\begin{tabular}{|r|l|}
\hline Journal: & Journal of Earthquake Engineering \\
\hline Manuscript ID & UEQE-2016-2293 \\
\hline Manuscript Type: & Technical Notes \\
\hline Complete List of Authors: & $\begin{array}{l}\text { Bernuzzi, Claudio; Politecnico di Milano } \\
\text { Di Gioia, Arturo; Metalsistem S.p.A. } \\
\text { Gabbianelli, Giammaria; Università degli Studi di Pavia } \\
\text { Simoncelli, Marco; Politecnico di Milano }\end{array}$ \\
\hline Keywords: & $\begin{array}{l}\text { pushover analysis, shelving rack storage systems, semi-continuous } \\
\text { unbraced frames, design assisted by testing, component tests, numerical } \\
\text { simulations }\end{array}$ \\
\hline
\end{tabular}




\section{PUSHOVER ANALYSES OF STEEL STORAGE SHELVING RACKS}

Claudio Bernuzzi (1), Arturo di Gioia (2), Giammaria Gabbianelli (3), Marco Simoncelli (1)

1. Dept. of Architecture, Built Environment and Construction Engineering, Politecnico di Milano, Piazza Leonardo da Vinci, 32, 20133, Milano, Italy.

2. Metalsistem S.p.A., Viale dell'industria, 2, 38068, Rovereto (TN), Italy.

3. Dept. of Civil Engineering and Architecture, Università degli Studi di Pavia, Via A. Ferrata, 3, 27100, Pavia, Italy.

SUMMARY - Among the various types of industrial solutions used to store goods and products, the light duty hand loaded shelving rack (SR) typology represents a very popular solution for domestic applications, libraries and for superstores/markets open to the public. Despite the limited cost, an eventual collapse could result in significant damage of stored goods, injuries and potentially the loss of human life, with the possible consequence of a long suspension of commercial activities. This reflects directly on the great importance of a correct design that, despite the large use of SRs, is nowadays developed with approaches characterized by inadequate levels of reliability.

A research program on $S R$ s is currently in progress in Italy, with the aim of improving the rules for both static and seismic design and this paper presents a combined experimentalnumerical study. Both component and pushover tests have been carried out, that are shortly summarized. Overall frame response has been simulated by means of advanced finite element software able to capture key features of the non-linear response of slender frames with monosymmetric cross-section members.

Keywords: shelving rack storage systems, semi-continuous unbraced frame, design assisted by testing, component tests, push-over analyses, numerical simulations.

\section{INTRODUCTION}

Among the various types of cold-formed racks used to store goods and products nowadays offered from manufactures to the market [Tilburgs, 2013], it is worth mentioning shelving rack storage systems, simply identified in the following as shelving racks or SRs. They represent a very popular solution, being commonly used for archive storage and domestic applications as well as for environments open to the public, such as shops, libraries and superstores. Despite their limited height and the modest weight of what is stored, SR safety is extremely important. An eventual failure might result not only in the damage of stored goods, but also in severe injuries and loss of human life, with a potential consequence being the immediate and possibly long suspension of commercial activities.

The SR frames are composed of uprights, diagonals and horizontal spacer bars, which are available on the market for varying depth and height. Furthermore, a key feature of modular SRs is that the number of loading levels and their spacing is highly customizable for any given frame height. Shelves are usually connected directly to the uprights by means of bolts, lugs or clips, or may be supported directly on beams. Down-aisle (longitudinal) stability may be achieved by the action of semi-rigid joints between the beams and the uprights [ECCS 67 , 1992], which is the case of interest herein considered (figure 1), or by bracing or sheeting in the spine of the rack. In the cross-aisle (transversal) direction, stability is provided by bracing or sheeting. A typical arrangement for SRs is presented in figure 1. It appears that, from a structural point of view, SRs differ from selective pallet racks in terms of the small sizes and limited weight of the components and for the modest width and height of the storage system. Other key features of SRs are the weight of the stored units, which are always lower than those characterizing other storage systems, and the high percentage of the holes and their small pitch along the upright (figure 2). 
Link_figure1

Several years ago SRs were classified as secondary systems and therefore no specific design computations were required to be developed by rack manufacturing engineers. Nowadays, due to the great presence of these ultra-light storage systems, as well as the increasing importance of their safe in-service use, a specific code has been developed for their design [FEM 10.02.06, 2012] but, like for provisions regarding other types of storage systems [EN 15512, 2009; FEM 10.02.07, 2011], further improvements are urgently required. It is in fact necessary to increase the level of reliability of the design rules currently adopted, particularly the fact that in all the design phases some of the key features associated with the use of thin-walled cold-formed profiles with a mono-symmetric cross-section are being neglected or insufficiently considered. The Annex A of the SR provisions addresses design assisted by testing, in which it is stated that full-scale tests should be carried out to determine the load carrying capacity (strength test) or to verify a target performance (acceptance test) of the SR frame.

\section{Link_figure2}

Experimental results should be used to extrapolate the design load carrying capacity of a family of structures similar to those tested but the test specimen itself should be the weakest configuration. It appears that the experimental assessment of the SR performance is undesirable for the following reasons: i) excessive costs, and ii) extremely limited field of validity of the results. Full-scale tests are expensive because they require experienced technicians, suitable experimental equipment and refined measuring systems. The direct consequence is that, generally, the available manufacturing budget restraints allow manufactures to test only a very limited number of geometric layouts. Furthermore, the extrapolation of the experimental data to configurations differing in terms of geometry (story height and load levels configuration, upright frame width and bay length) and/or material components does not seem adequately reliable. On the other hand, the use of numerical approaches, based on experimental data regarding the performance of key components, seems a more efficient approach to achieving the goal of a safe design. However, this is only the case if advanced finite element (FE) beam formulations are available to capture the response of mono-symmetric cross-section members. Up to now, researchers have not paid adequate attention to SRs, with the exception of Trouncern and Rasmussen [2014] who tested under compression two different types of SR uprights by varying the specimen length and focusing attention on the combined effects of local and distortional buckling.

An academic research project that started a few years ago, in collaboration between the Politecnico di Milano and the University of Pavia, aimed at contributing to the improvement of the design rules currently adopted for industrial storage systems. Attention had been paid first on the static design [Bernuzzi 2015a] and then, in the phase which is currently in progress, on the procedures adopted for seismic design. This paper presents the results of a combined experimental-numerical study on SRs that are unbraced in the longitudinal direction. In addition to component tests, eight representative configurations differing in terms of components (uprights and joints) and loads have been investigated by carrying out full-scale pushover and free vibration tests. The experimental results have then been simulated by means of advanced FE software, specifically developed for modelling industrial storage systems with non-symmetric cross-section components.

\section{THE COMPONENTS TESTS}

Component tests have been carried out on uprights and joints (beam-to-column and baseplate connections) with the goal of providing essential data for the design of complete framed systems. The well-established importance of these tests is fundamental not only for 
monotonic design but also in the case of structures subjected to earthquakes. As an example, if advanced FE analysis packages are available, the whole storage rack could be efficiently modelled to obtain the pushover curves numerically, instead of evaluating them experimentally, and thus significant costs could be avoided. Furthermore, if the model is able to reproduce the experimental response, extensive parametric analyses could be carried out with limited costs and cover a wide range of practical interest.

In the following, attention has been focused on two typologies of SRs, differing in terms of the thickness of the components (uprights, beams, battens and lacings). Labels F1 and F3 identify the thinner and the thicker ones, respectively and the ratio between the F3 and the F1 thickness is 1.8. All the key data, from the cross-section geometry to the overall response, are herein presented in non-dimensional form for reasons of commercial sensitivity to avoid public discolure of data related to the commercial products employed. Although the authors were requried to maintain a certain level of confidentiality, the research outcomes still maintain their validity and interest for routine design.

\subsection{Upright tests}

The considered uprights, as shown in table 1, have an approximately tee-shaped crosssection, with flange stiffeners and perforation that are wide and long when compared with the pitch. The main geometric data of the cross-section of the two considered uprights are provided in the table, which are the ratios between the gross $\left(A_{g}\right)$ and the perforated $\left(A_{\text {perf }}\right)$ cross-section areas and the ratio between the second moment of area in the two principal direction $\left(I_{y} / I_{z}\right)$. In the table the value of the Saint Venant's torsional constant $\left(I_{t}\right)$, the warping constant $\left(I_{w}\right)$ and the ratio between the eccentricity of the shear center with respect to the centroid $y_{s}$ and the coil thickness $(t)$ are also reported.

\section{Link_table 1}

Owing to the scope of the study, which is to assess the accuracy in the numerical prediction of the experimental full-scale pushover relationships, attention has been focused on the tests necessary to characterize the response of the uprights.

Axial behavior has been investigated by means of stub column tests according to the requirements of Appendix A of the EN 15512 standard [CEN EN15512, 2009], in order to evaluate the effective area accounting for perforations, cold-manufacturing processes, connection points/zones, overlapping and local and distortional buckling phenomena. The typical specimen is composed of a stub upright, at each end of which a thick steel plate is welded. On the basis of the failure load $\left(R_{d}\right)$, the effective area, $A_{\text {eff }}$, however limited to be not greater than the gross one $\left(A_{g}\right)$, is evaluated as:

$$
A_{\text {eff }}=\frac{R_{d}}{f_{y}}=Q^{N} \cdot A_{g}
$$

where $f_{y}$ is the yielding strength of the base material before the cold working processes and $Q^{N}$ is the reduction factor accounting for buckling on stocky thin-walled members.

In figure 3 a typical layout of a stub-column test is depicted, together with a F1 specimen at collapse under the testing machine.

\section{Link_figure3}

The reference values of the experimental reduction factors $Q^{N}$ are 0.63 and 0.79 for $\mathrm{F} 1$ and F3 uprights, respectively, confirming the non-negligible influence of the extensive perforation system on this type of upright.

As to the bending behavior, the EN15512 provisions suggest bending beam tests for the prediction of the flexural performance of the uprights about the principal axes of flexure. In particular, from the experimental load versus mid-span displacement curve, the values of the effective second moments of area and of the bending resistance can be directly assessed, 
which are important design parameters that account for the presence of regular perforations in members. If attention is focused only on the upright flexural stiffness, owing to the fact that resistance can be conservatively evaluated making reference to the perforated cross-section, a simple free vibration test coupled with numerical FE simulations should result in an efficient and inexpensive alternative, which has been used in the present study. In particular, simplysupported beam specimens with a $2 \mathrm{~m}$ bay length have been suitably excited by means of a rubber hammer in order to capture the flexural behavior in all cross-section directions (Fig. 4a). A tri-axial accelerometer, MEMS microchip LIS344 [website with datasheet, 2016], fixed at the specimen mid-span and connected to an Arduino Uno acquisition data logger, has been used (Fig 4b). In figure 4c) a typical output in term of acceleration-time relationship is provided. Finally, the time history of accelerations acquired by the data logger has been converted in frequency domain via Fast Fourier Transform (FFT) functions, as shown in figure $4 d)$.

\section{Link_figure4}

The value of the effective second moment of area, $I_{\text {eff, }, k}$, has been evaluated by the assessment of the circular frequency, $\omega_{k}$, (with $\mathrm{k}$ indicating the $y$ or $z$ direction of vibration), or equivalently, of the natural frequency $f_{k}$, according to the well-established theory on dynamics of structures [Paz, 1985]:

$$
\omega_{k}=\frac{2 \pi}{f_{k}}=\pi^{2} \sqrt{\frac{E_{d} I_{e f f, k}}{m L^{4}}}
$$

where $E_{d}$ is the dynamic Young's modulus, $m$ is the specimen mass per unit length and $L$ is the length between the supports.

During re-elaboration of test data, it has been noted that, due to the low energy dissipation capacity of uprights, damped and natural frequencies were very similar, with the assessed damping ratio always lower than $1 \%$. In table 2 the results in term of fundamental frequency $(f)$ are presented.

Link_table2

As shown in the table, the ratio $f_{\mathrm{y}} / f_{\mathrm{z}}$ is significantly greater than unity: 2.18 and 2.27 for F1 and F3 uprights, respectively. Being $\frac{\omega_{y}}{\omega_{z}}=\sqrt{\frac{I_{e f f, y}}{I_{e f f, z}}}$ according to eq. 2) also in case of flexural performance, a remarkable influence of the direction of bending is expected owing to the great difference between $I_{\text {eff, } y}$ and $I_{\text {eff, } z}$. The ratio of the second moments of area, which for the gross cross-section ranges from 6.6 to 6.7 , reduces to 4.77 and 5.14 for F1 and F3 uprights, respectively.

As the free vibration test is not yet standardized in design provisions, the authors decided to numerically validate experimental outcomes by means of the FE general purpose analysis package Abaqus [Abaqus, 2014]. Shell models with more than 10000 S4R type elements have been used to accurately reproduce the sequence of gross- and perforated-sections, hence allowing the complex flexural behavior of the uprights to be captured (figure 5). The effective second moments of area are evaluated on the basis of upright deflection under the considered load condition.

\section{Link_figure5}

Numerical (num) and experimental (exp) results are summarized in table 3 in terms of the ratio between effective (subscript eff) and gross cross-section properties along both the 
principal axes. Effective area and second moment of area about the y-axis are predicted very accurately, while in case of bending along z-axis, the errors are lower than $10 \%$, but on the safe side, confirming that the vibrational approach should be a very attractive alternative and more than adequate for practical design purposes.

$$
\text { Link_table3 }
$$

\subsection{Tests on connections}

Beam-to-column and base-plate joints have a great influence on the shelving rack response as well as on other types of industrial storage systems, [Baldassino and Bernuzzi, 2000]. In the following the results associated with both types of tests are shortly summarized.

Beam-to-column joints. According to the requirements of Appendix A of EN15512, joint tests have been carried out on cantilever specimens that are composed of a one-way node (a short column connected to a beam) loaded by a shear force applied at the beam end, generating a bending moment on the joint. In figure 6 , the results in term of non-dimensional moment-rotation $(\bar{m}-\bar{\phi})$ curves are reported.

Link_figure6

The moment $(M)$ and the rotation angle $(\phi)$ have been proposed in dimensionless form by using the criterion reported in EC3-1-8 [CEN EN1993-1-8, 2005]:

$$
\begin{aligned}
& \bar{m}=\frac{M}{W_{g, b} \cdot f_{y}} \\
& \bar{\phi}=\phi \frac{E I_{b}}{W_{g, b} \cdot f_{y} \cdot L_{b}}
\end{aligned}
$$

where $I_{b}$ and $W_{g, b}$ are respectively the second moment of area and the elastic section modulus of the gross cross-section of the beam with length $L_{b} . f_{y}$ is the yielding tension and $E$ is the Young's modulus.

In the figure, two regions can be clearly identified: one for the hinges and the other for semi-rigid joints divided by a boundary that is represented as an elastic-perfectly plastic $\bar{m}-\bar{\phi}$ relationship. It is characterized by a non-dimensional rotation and bending resistance values at the yielding point equal to 0.5 and to 0.25 , respectively. Beam-to-column joint responses are always located in the hinge domain at significant distance from the semi-rigid domain. The initial branch of the $\bar{m}-\bar{\phi}$ curves is always very close to the joint model boundary but as the bending moment increases, the flexural stiffness decreases owing to the spread of plasticity in the hooks of the connection details. Bending resistance is always very limited, but at the same time, non-negligible from the design point of view, corresponding to approximately $10 \%$ of the bending resistance of the beam. Dashed lines indicate the multilinear relationships deduced from the experimental test and used for the numerical simulation described in section 5 .

Base-plate connections. Two different types of base restraints (figure 7) are usually offered by the manufacturer, which can be identified as $S$-(support) and $F$-(fixed) restraints, independently on the thickness of the uprights. In the first case, the end of the upright is connected to a very thin plate simply supported on the floor. In the second case, the end part of the upright is mechanically connected to the web of a T plate, whose flange is attached via two mechanical or chemical fasteners to the floor slab.

Link_figure7

URL: http:/mc.manuscriptcentral.com/ueqe Email: bgencturk@uh.edu 
Base-plate connection tests according to the EN15512 code require complex testing equipment to evaluate the moment-rotation curves for different values of the axial force, which were not available for the present research. As an alternative the authors made reference to a simple portal frame test on a spatial specimen (Fig. 8a) composed of two short upright frames $(\mathrm{h}=290 \mathrm{~mm})$ with the pallet unit hinged to the uprights (Fig. $8 \mathrm{~b}$ ) and directly loaded by the sustained pallet unit load. A lateral force is increased from zero until collapse of the specimen or the achievement of a level of deformation that is beyond the range of engineering interest. The end restraint details for the $S$ - and $F$ - base joint types are presented in figures $8 \mathrm{c}$ ) and $8 \mathrm{~d}$ ), respectively. The rigid floor condition has been achieved by bolting the base plate of each $F$-joint to a very stiff and thick steel plate. Otherwise, in case of $S$ joints, the thin plate at the upright end is simply supported on the floor plate.

\section{Link_figure8}

The mass of pallet units (corresponding to a gravity load W), was kept constant during the tests, which have been carried out by increasing the lateral push force (F) and measuring the horizontal top displacement $(d)$ at the center of the bay. Owing to the high level of accuracy and precision of the geometry of the tested specimens, the vertical $(N)$ and horizontal $(V)$ load acting on each upright can be directly assumed to be equal to:

$$
\begin{aligned}
& N=W / 4 \\
& V=F / 4
\end{aligned}
$$

Due to the circular bars (simulating cylindrical hinges) at the top end of upright frames, the response of each upright of the specimen is assumed to be that of a cantilever beam loaded on the top and with a rotational spring at the base. Therefore, the very limited contribution of shear deformations is neglected and the elastic top displacement $\left(\delta_{u}\right)$ is assessed as:

$$
\delta_{u}=\frac{V h^{3}}{3 E I_{u}}
$$

The upright axial deformations were considered negligible due to the very limited height of the specimen and hence the base plate rotation $\left(\phi_{\text {base }}\right)$ can be assessed as:

$$
\phi_{\text {base }}=\arctan \left(\frac{d-\delta_{u}}{h}\right)
$$

Bending moment acting on the base plate, considering both first and second-order effects is:

$$
M_{\text {base }}=V h+N d
$$

Also for base-plate connections, like for the beam-to-column joints, reference is made to the non-dimensional $\bar{m}-\bar{\phi}$ curves, which are presented in figures 9 and 10 , related to the $F$ and $S$-type bases, respectively. Dashed lines in figures 9 and 10 represent the multi-linear constitutive laws adopted to simulate the push-over responses. The straight line close to the moment axis is related to the boundary between semi-rigid and rigid base joints characterized by a stiffness and a strength equal to 30 times the flexural stiffness and to the bending resistance of the upright, respectively. With reference to the fixed bases (Fig. 9), it appears that the base joint responses are typically semi-rigid and the limit resistance is approximately two times lower than the upright flexural resistance of the gross cross-section. Furthermore, it can be noted that there is a limited influence of the axial load on the fixed base restraints, which moderately increase the joint performance with the increase of the applied axial load. Failure was due to plasticity at the upright end and at the flange of the T plate.

$$
\text { Link_figure9 }
$$

Similarly, the results related to the $S$-type connections are reported as non-dimensional $\bar{m}-\bar{\phi}$ curves in figure 10 . As expected, the responses are remarkably more flexible than the response associated with the rigid bases, and for this restraint the curves are strongly 
influenced by the values of the axial load. Flexural base strength is quite proportional to the level of axial force and ranges from approximately $5 \%$ to $25 \%$ of the upright bending resistance. Failure of the joints was due to the plasticity in the thin-end plate, equal for the S1 and S3 uprights, which remained elastic.

\section{Link figure 10}

\section{FULL SCALE TESTS}

The experimental program was comprised of 8 full-scale tests on specimens that all have the same geometric configuration, that is 2 bays and 4 stories (figure 11). The length of the bay is $1210 \mathrm{~mm}$ and the inter-story height is approximately $500 \mathrm{~mm}$, with a total height of $1972 \mathrm{~mm}$.

Link_figure 11

The width of the upright frame is $500 \mathrm{~mm}$, which is of a mixed type: near to the floor there is cross-bracing with lacings while in the remaining part battens connect the uprights. Differences among the specimens are mainly due to:

- components: two sets of components (beams, uprights and lacings) have been considered for uprights and beams, which, as previously mentioned, are identified as $\mathrm{F} 1$ and F3 and differ for the thickness of the coils;

- base connection restraints: the supported $(S$-) and fixed $(F-)$ bases, which represent the common solution for upright end connections, have been investigated together with ideal hinges $(H-)$ at the upright bases. This limiting condition can very rarely be reached due to the presence of a continuous floor and to the benefits associated with the upright axial load. Like for the $F$ - type bases the upright bottom end is strengthened by a $\mathrm{T}$ member, but no bolts were used to fix its flange to the thick supporting plate, which was free to rotate in the down-aisle rack direction (Fig. 12);

- vertical load: equal gravity loads were applied on each bay and different values have been selected to simulate the weight of the stored goods, depending on the rack types and on the base restraints.

Link_figure12

Table 4 summarizes key features of the tested specimens in terms of components, base restraint and value of the masses on each couple of pallet beams and presents the labels used for their identification. In the same table, the value of out-of-angle imperfection expressed in milliradians along the down- and cross-aisle direction are also reported and identified as Imp_D and Imp_C, respectively.

Link_table4

\subsection{Free vibration tests}

Prior to pushover tests, free vibration tests have been carried out on each specimen via MEMS accelerometers. A rubber hammer was used to excite the frames in order to evaluate the first (fundamental) period in the longitudinal direction, $\mathrm{T}_{1}$, which is presented in table 5 for the unloaded and loaded (gravity loads only) conditions before the pushover tests.

\section{Link_table5}

For the unloaded specimens, as expected, the lowest and the highest values of $\mathrm{T}_{1}$ are associated with the $\mathrm{H}$ - and F-type bases and the influence of the base restraints is nonnegligible. Differences in $\mathrm{T}_{1}$ for the $S a$ and $S b$ specimens, which should be nil, are due to the 
presence of the geometrical imperfections, as confirmed also by value of the out-of-plumb angles presented in table 4 . In the loaded conditions, $T_{1}$ is significantly higher, from 7 to 10 times, than for the unloaded case. As to the F1 specimens, it can be noted that, with the mass of $100 \mathrm{~kg}$ per bay, the period of the hinged specimen $(S b)$ is longer than for the $S a$ case. Increasing the mass to $200 \mathrm{~kg}(S a), \mathrm{T}_{1}$ increases significantly with respect to $S b$ and the $F$ specimen, which has the same mass, is significantly stiffer than $S a$, due to the resistance provided by the fixed bases. Periods associated with the F3 specimens are lower than the corresponding F1 periods, due to the larger value of the component thickness. A direct comparison with the same masses per bay can be considered for the $F$ and $S a$ specimens, with the former slightly stiffer than the latter, and to the $\mathrm{H}$ and $S b$ racks, the first more flexible than the second due to the hinged base.

\subsection{Pushover tests}

Overall frame tests have been carried out by pushing racks in the down-aisle direction using a hydraulic jack. Loads have been applied on each level in order to simulate an inverse triangular pattern that increases from the bottom to the top via the load balancer indicated in figure 13. Tests were carried out by increasing the value of the applied horizontal forces until collapse was achieved and/or the deformed shape of the rack was in the softening branch and beyond the range of interest for engineering purposes due to the large values of horizontal displacements.

\section{Link_figure13}

The measuring system consists of a load cell used to monitor the total applied lateral load and inductive transducers to monitor the lateral displacements of each storage level. Top displacement was used as the control test parameter. A counter frame, approximately $3.0 \mathrm{~m}$ high, $5.0 \mathrm{~m}$ long and $1.2 \mathrm{~m}$ wide, indicated in figure 14 , consisted of a spatial fully braced frame (trussed tower) constructed using bi-symmetric rectangular hollow section members and connected via a rigid and strong beam to an upright frame. The counter frame serves essentially to apply to the specimen the lateral load and it has been rigidly fixed to an industrial foundation. In order to avoid possible damage due to a sudden and brittle collapse of the specimens, the masses simulating the effects of gravity loads have been attached to a crane by means of steel cables.

\section{Link_figure14}

Figures 15 and 16, which are related to the F1 and F3 frames, respectively, present the experimental $\bar{v}^{\exp }-\delta^{\text {exp }}$ relationships, where $\bar{v}^{\exp }$ is the non-dimensional base shear and $\delta^{\text {exp }}$ is the horizontal displacement at the top of the rack. The term $\bar{v}^{\text {exp }}$ has been expressed as the ratio between the total base shear applied to the frame $\left(V_{b}^{\exp }\right)$ over the maximum base shear reached on the $S a$ specimens, i.e. $\bar{v}^{\exp }=\frac{V_{b}^{\exp }}{V_{b, \max }^{S a}}$.

Link_figure15

Link_figure16

Both figures present similarities in all the pushover curves. The initial stiffness depends only on the type of rack and due to the stabilizing action of the gravity loads is not strongly influenced by the efficiency of the base restraints. Increasing the applied lateral loads, the stiffness of the specimen decreases until the maximum resistance is reached and then a softening branch can be observed. The best and worst performances are associated, as expected, to the F- and H-cases, respectively and the responses of the S-specimens are in 
between but closer to $\mathrm{H}$ specimens. The influence of the vertical loads can be directly observed by comparing the $S a$ and $S b$ specimens, which are loaded with the heaviest and lightest masses, respectively. No great differences can be observed in the value of the stiffness, while the maximum applied lateral force is greater in the case $S b$, up to 1.2 times larger than for the $S a$ specimens. To evaluate the influence of the thickness of the material of the specimen performance, figure 17 can be considered, where the pushover curves for the F1 and F3 specimens are presented in dimensional form for the cases of F- and H-base restraints. Despite the absence of the values on the ordinate axis scale which have been omitted for reasons of commercial sensitivity, it can be noted that an increase of $80 \%$ of the thickness lead to a maximum shear for F3 specimens that was more than 3 ( $F$ bases) and 6 ( $S$ bases) times greater than the corresponding F1 values.

Link_figure17

Tests were stopped when the end stroke of the hydraulic jack was reached and brittle failures were never observed.

Link_figure18

All the specimens sustained a large global deformation in the plastic range, between the yield and ultimate collapse loads (Fig. 18), mainly provided by the inelastic deformations of beam-end connectors as shown in figure 19.

Link_figure19

A relevant contribution in terms of ductility was due to the type of the base restraints and figure 20 show the typical deformed shapes of the restraints for the $F$-, $S$ - and $H$ - framed systems. As to the hinged bases, it can be noted that the plastic deformation of the thin plate is similar to that observed during base-plate connection tests.

Link_figure20

A summary of the test data related to the maximum base shear and the associated level of lateral displacements is reported in table 6, for each specimen. Also reported are the nondimensional values of the shear force $\left(\bar{v}_{\max }^{\exp }\right)$ and displacement value $\left(\delta_{\max }^{\exp }\right)$, the values of the inter-story drift, $\Delta_{\mathrm{j}}$, and the inter-story drift ratio, $\Delta_{\mathrm{j}} / \mathrm{h}_{\mathrm{i}}$. Independent of the type of bases, a non-negligible level of lateral displacement was reached in each specimen. The lowest values are associated with the F1-Sa and F3-Sa specimens and using $H_{\text {tot }}$ to indicate total height, the values of the ratio $\delta_{\max }^{\exp } / H_{\text {tot }}$ are $1 / 39$ and $1 / 23$, respectively. The largest value of $\delta_{\max }^{\exp } / H_{\text {tot }}$ is approximately $1 / 14$, which was reached both for F1- $F$ and F3- $F$ specimens.

Link_table6

The deformed shape of each specimen is of the panel mechanism type, which is always governed by the rotation of the joints with all the uprights only inclined, as confirmed from movies taken during the tests. Similar remarks can be made based on figure 21, where lateral displacements are plotted versus the storage level.

Link_figure21

\section{NUMERICAL SIMULATIONS WITH ŚIVA SOFTWARE}


As already observed in previous research on rack performance [Bernuzzi et al. 2015b, 2014] under static loads, the influence of warping effects must always be accounted for when mono-symmetric open thin-walled members are used as uprights. As a consequence, independent of the complexity and extension of the geometric layout, refined FE analysis packages are also required in routine design. Owing to the non-coincidence between the shear center $\mathrm{S}$ and the centroid $\mathrm{G}$, in the case of mono-symmetric cross-sections, reference is generally made to point $\mathrm{S}$ for the definition of the sets of generalized displacements, except for the axial displacement $u$, which is assumed to coincide with point $\mathrm{G}$. The shear forces $\left(F_{y}\right.$ and $F_{z}$ ), uniform torsional moment $\left(\mathrm{M}_{\mathrm{t}}\right)$, and bimoment $(B)$ are referred to point $\mathrm{S}$, whereas bending moments $\left(M_{y}\right.$ and $\left.M_{z}\right)$ and axial force $(N)$ are defined with respect to the centroid, as depicted in figure 22. Cross-section warping $\theta$, which is the $7^{\text {th }}$ DOF, is essential to correctly model open singly-symmetric cross section members and is defined as:

$$
\theta=\theta(x)=-\frac{d \varphi_{x}}{d x}
$$

Only the presence of $\theta$ guarantees that the rack design is developed using appropriate analysis tools and adequately considering the key features of rack upright cross-sections, the geometry of which is accurately described by the Wagner constants and the eccentricity between points $\mathrm{O}$ and $\mathrm{S}$.

Link_figure22

In the context of the present research, the experimental behavior of the tested SRs has been reproduced by using the Siva FE analysis program, which is based on the Fortran code NONSAP but suitably modified. Non-linear springs are implemented to reproduce the behavior of connections and hence it is possible to simulate the behavior of moment-resisting frames, where plasticity can be concentrated in correspondence of the beam-to-column joints and at the base of the columns (at the base-plate connections). As to the details related to the rack modelling:

- both beam-to-column joints and base-plate connections have been simulated via a mono-dimensional rotational spring element. The multi-linear (5 branches) moment-rotation relationships are represent by the dashed lines in figures 6 (beam-to-column joints), 9 (F1-bases) and 10 (F3-bases).

- members have been modelled via a 7 DOFs beam elements and the geometric properties refer to the gross cross-section, according to the requirements of common design codes.

- the vertical loads simulating the presence of pallet units have been modelled as uniform distributed loads on the pallet beams.

Initially the free vibration tests were simulated and table 7 presents the ratio between the experimental and numerical fundamental period of vibration $\left(T_{1}\right)$ for the loaded and unloaded racks and the percentage of the participating mass associated with the first mode of vibration (evaluated numerically). From the data, it appears that the accuracy of Siva in the prediction of the fundamental period of vibration is more than satisfactory. Errors range from $2 \%$ to $25 \%$ and should be easily reduced by increasing the number of experimental tests. Furthermore, owing to the absence of longitudinal bracing systems, the fundamental mode is always associated with a flexural cantilever deformed modal shape. The participating mass ranges between $75 \%$ and $85 \%$. As a consequence, the common inverse triangular lateral force distribution can be adopted for pushover analysis.

\section{Link_table7}

Eigenvectors associated with the dynamic eigenvalues are similar for all the considered specimens and, as an example, in figure 23 the $1^{\text {st }}$ and $2^{\text {nd }}$ mode shapes for the $\mathrm{F} 1-F$ frame are depicted, which are always related to the longitudinal and transversal directions of vibration, respectively. 


\section{Link_figure23}

The numerical pushover curves $\bar{v}^{\text {num }}-\delta^{\text {num }}$ are compared with the $\bar{v}^{\exp }-\delta^{\exp }$ experimental ones in figures 24 and 25, which are related to the F1 and F3 specimens, respectively. In the figures, which are divided into four parts, each associated with one of the four tested specimens, the degree of utilization (DUJ) is presented for each joint. It is expressed as the ratio between the bending moment at the joint over the flexural resistance evaluated with reference to the maximum applied base shear.

Link_figure24

It can be noted that, at first, the degree of accuracy of the numerical simulation is more than satisfactory for design purposes. The initial branch of the pushover curves is accurately reproduced, as well as the trend of the experimental curve, including also the softening branch.

Link_figure25

Differences in components, base-plate joints and load conditions with the numerical approach are reflected in different pushover curves, as experimentally observed. A check of the coefficient of utilization of the uprights shows that they are in elastic range during the pushover analysis, confirming the key role played by the ductility of connections. The failure condition of the specimens, which can be associated with the maximum lateral load applied, is due to interaction between plasticity and instability. For the sake of simplicity, in the following the labels PBH and PBS are introduced to indicate the beam-to-column joints subjected to hogging and sagging moments, respectively, under lateral load. In particular, it can be noted that:

- base-plate connections are always in the plastic range (DUJ=1);

- the values of DUJ for PBH and PBS are independent of the bay and load level, with the exception of the PBS joints at the first load level in the F1-F specimen, characterized by a DUJ slightly lower than at the other levels;

- all beam-to-column joints are in elastic range, with the exception of the PBH joints of the $F 3-F$ specimen, with DUJ=1 for each level.

Table 8 summarizes the key data required for an appraisal of the accuracy of the Siva 7DOFs simulations, with results expressed in terms of the numerical values (subscript num) over the experimental values (subscript exp). In particular, reference is made to the accuracy in the prediction of the initial stiffness $(k)$, which has been evaluated by interpolating via a straight line the sets of numerical and experimental results according to the minimum square root method. A regression coefficient not lower than 0.95 has been imposed. It can be observed that the errors are always very limited, in particular the overestimation is not greater than $5 \%$. The ratios related to the numerical versus the experimental maximum shear base are also reported in the table. The $\frac{V_{b, \max }^{\text {num }}}{V_{b, \max }^{\exp }}$ ratio ranges between 0.87 and 1.14 , confirming that the degree of accuracy is more than adequate for design purposes.

$$
\text { Link_table8 }
$$

\section{CONCLUDING REMARKS}

Shelving racks (SRs) represent the lowest level of storage systems in terms of dimensions, costs and weight of the stored goods and products. They are commonly and extensively used worldwide, despite the fact that they are designed neglecting some key 
features of the structural behavior. Current design approaches are, in fact, based on extremely poor rules and standard codes are in need of urgent improvements, especially to adequately account for earthquake excitation.

This paper summarizes a combined experimental and advanced numerical analysis. In particular, the experimental phase, which was briefly summarized, allows for the evaluation of the key features of the response of isolated components as well as of the whole set of different specimens tested under push-over loads. The more than satisfactory agreement observed in the numerical simulations of test data confirms the adequacy of the Siva FE software in modelling racks. More in general, the evidence of the accuracy in the simulation of experimental overall behavior, based on only component test results, opens the ways for the extensive numerical simulations [Bernuzzi et al., 2016] necessary to improve the seismic design rules for industrial storage racks.

\section{ACKNOWLEDGMENTS}

Authors would like to express their personal thanks to Mr. Antonello Briosi and dr. Lucio Gelmini of 'Metalsistem S.p.A.' where the experimental phase of this study has been carried out at the research and development division. The efforts and suggestions of Prof. Armando Gobetti (University of Pavia), who contributed substantially to the development of the Siva FE software, an essential component for the success of the present research, are much appreciated.

\section{REFERENCES}

Abaqus/standard [2014]. User's manual version 6.8, Hibbit, Karlsson ans Soresen, USA.

Baldassino, N. and Bernuzzi, C. [2000] "Analysis and behaviour of steel storage pallet racks", Thin-Walled Structures 37, 277-304.

Bernuzzi, C., Gobetti, A., Gabbianelli, G. and Simoncelli, M. [2014] "Warping influence on the resistance of uprights in steel storage pallet racks", Journal of Constructional Steel Research 101, 224-241.

Bernuzzi, C., Draskovic, N. and Simoncelli, M. [2015a] "European and United States approaches for steel storage pallet rack design. Part 2: Practical applications", Thin Walled Structures 97, 321-341.

Bernuzzi, C., Gobetti, A., Gabbianelli, G. and Simoncelli, M. [2015b] "Simplified approaches to design medium-rise unbraced steel storage pallet racks. I: Elastic buckling analysis", Journal of structural Engineering, ASCE 141(11), 04015036.

Bernuzzi, C., Gabbianelli, G., Russo, M. and Simoncelli, M. [2016] "On the assessment of the seismic performances of steel storage shelving racks", in preparation.

CEN, EN 15512 [2009] "Steel static storage systems - Adjustable pallet racking systems Principles for structural design”, CEN European Committee for Standardization, pp. 137.

CEN, EN1993-1-8 [2005] "Eurocode 3. Design of steel structures- Part 1-8: Design of joints" EN1993-1-8, Brussels, Belgium.

ECCS [1992], "Analysis and design of steel frames with semi-rigid joints", European Convention of Constructional Steelwork doc. n. 67.

FEM 10.02.06 [2012] "The design of hand loaded low rise steel static shelving” FEM racking and shelving product group.

FEM 10.02.07 [2011] "The design of drive-in and drive-through racking" FEM racking and shelving product group.

Paz, M. [1985], Structural Dynamics, Springer, second edition, New York.

Trouncern, A.N. and Rasmussen, K.J.R. [2014] "Flexural-torsional buckling of ultra lightgauge steel storage rack uprights", Thin Walled Structures 81, 159-174. 
Tilburgs, K. [2013] "Those peculiar structures in cold formed steel: "racking and shelving", Steel Construction 6 (n. 2), 95-106.

Website:

www.st.com/web/en/resource/technical/document/datasheet/CD00182781.pdf [2016].

\section{APPENDIX A: List of symbols}

Latin upper case letters

$A_{\text {eff }}=$ effective cross-section area.

$A_{\text {eff }}=$ effective cross-section area.

$A_{\text {perf }}=$ perforated cross-section area.

$\mathrm{DUJ}=$ degree of utilization of joints.

$\mathrm{E}=$ Modulus of elasticity of steel.

EC3 = EN 1993-1-1 Eurocode 3 "Design of Steel Structures".

$\mathrm{F}=$ fixed.

$\mathrm{F}=$ lateral force.

FFT $=$ Fast Fourier transform.

$\mathrm{G}=$ shear modulus.

$\mathrm{H}=$ hinged.

$I_{\text {eff }}=$ effective second moment of area.

$I_{y}, I_{z}=$ second moment of area.

$I_{t}=$ Saint-Venant torsion constant.

$I_{w}=$ warping constant.

$K=$ effective length factor.

$\mathrm{L}=$ member length.

$M=$ bending moment.

MEMS $=$ micro electro-mechanical system.

$\mathrm{PBH}=$ beam-to column joint subjected to hogging moment.

PBS = beam-to column joint subjected to sagging moment.

$Q^{N}=$ reduction factor.

$R_{d}=$ resistance.

$\mathrm{S}=$ simply supported.

$S_{j, b t c}, S_{j, \text { base }}=$ stiffness of connection.

$\mathrm{SR}=$ shelving rack

$\mathrm{T}_{1}=$ fundamental period.

$\mathrm{V}_{\mathrm{b}}=$ total base shear.

$V_{b}^{\text {exp }}=$ measured base shear.

$W_{g, b}=$ elastic section modulus of the gross cross-section.

$\mathrm{W}=$ pallet weight.

$\underline{\text { Latin lower case letters }}$

$e=$ eccentricity.

$\exp =$ experimental.

$f=$ frequency.

$f_{y}=$ specified minimum yield stress strength.

$\mathrm{h}=$ inter-story height.

Imp $=$ imperfection.

$k=$ stiffness.

$m=$ mass of specimen. 


$$
\begin{aligned}
& \text { num = numerical. } \\
& \mathrm{t}=\text { thickness. } \\
& \bar{v}^{\exp }=\text { non-dimensional base shear. } \\
& z_{\mathrm{S}}=\text { shear center eccentricity. }
\end{aligned}
$$

Greek letters

$\delta^{\exp }=$ measured displacement.

$\bar{m}=$ non-dimensional bending moment.

$\bar{\phi}=$ non-dimensional rotation angle.

$\delta_{u}=$ upright deformation.

$\Delta=$ inter-story drift.

$\phi=$ rotation angle.

$\omega=$ circular frequency. 


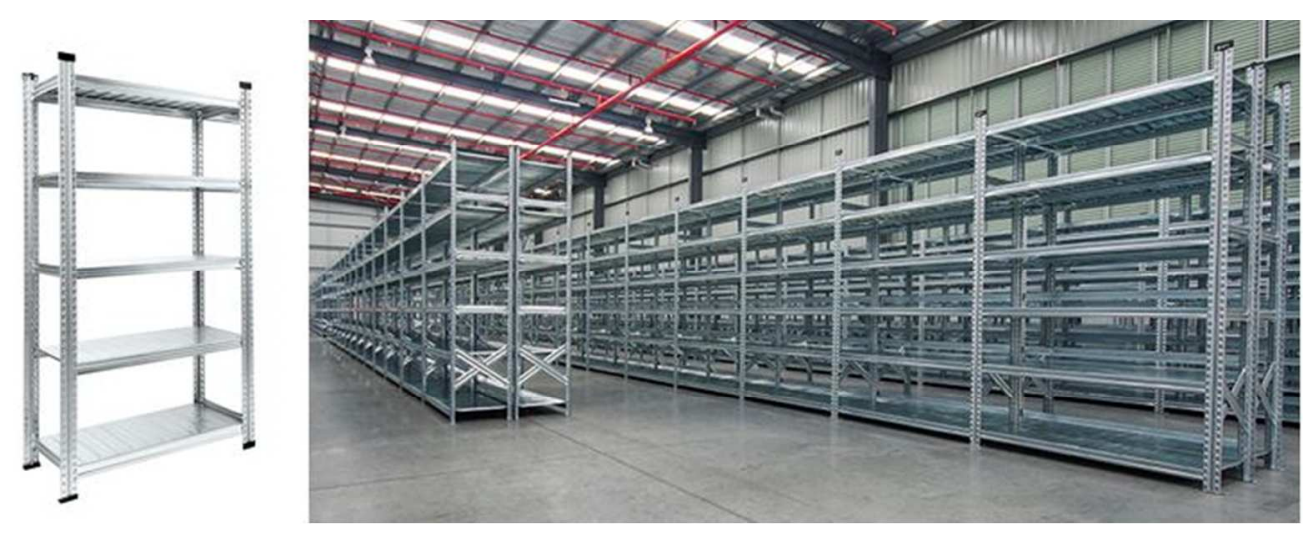

Figure 1. Typical SR systems and key components $61 \times 23 \mathrm{~mm}(300 \times 300$ DPI $)$ 


1
1
3
4
5
6
7
8
9
10
11
12
13
14
15
16
17
18
19
20
21
22
23
24
25
26
27
28
29
30
31
32
33
34
35
36
37
38
39
40
41
42
43
44
55
50
56
57
48
59
50
51
53
50

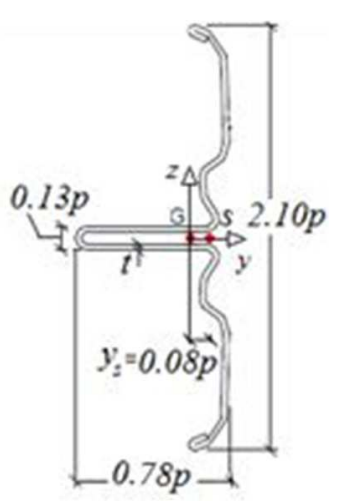

$10 \times 15 \mathrm{~mm}(300 \times 300 \mathrm{DPI})$

URL: http:/mc.manuscriptcentral.com/ueqe Email: bgencturk@uh.edu 

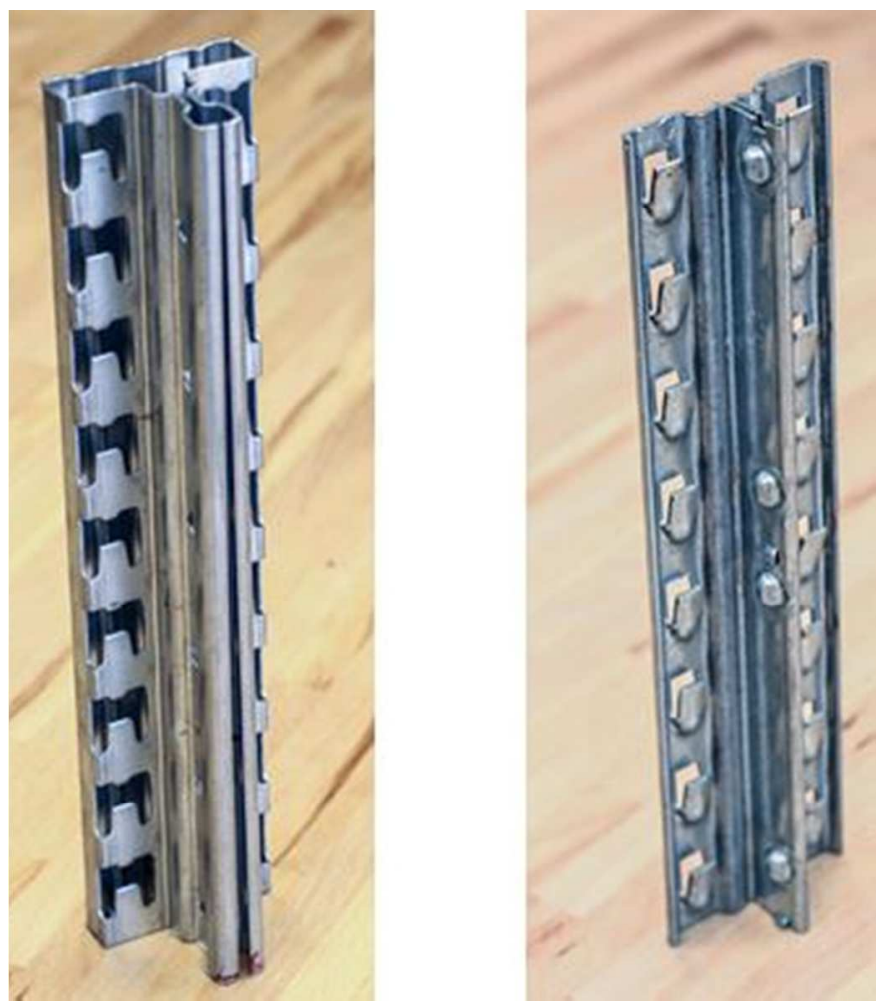

Figure 2. Typical SR uprights with the regular perforation system. $28 \times 32 \mathrm{~mm}(300 \times 300 \mathrm{DPI})$ 


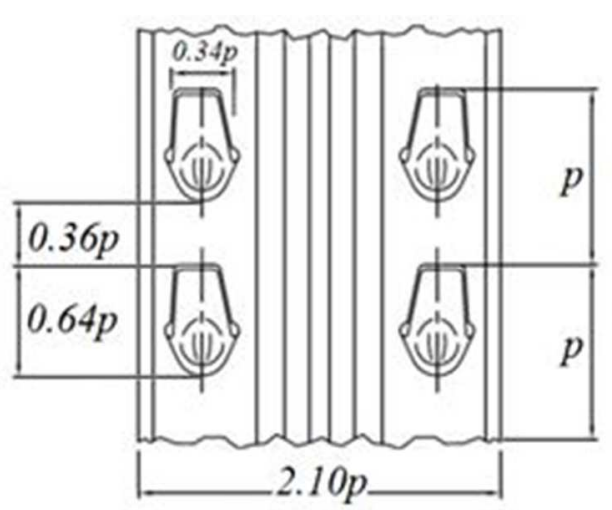

$20 \times 16 \mathrm{~mm}(300 \times 300 \mathrm{DPI})$ 


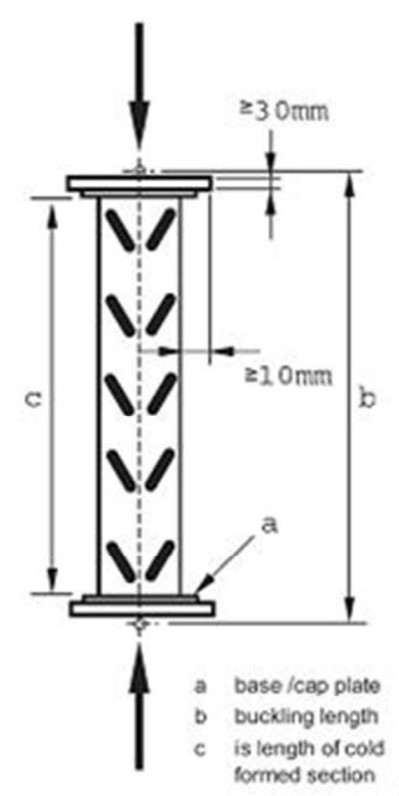

a)

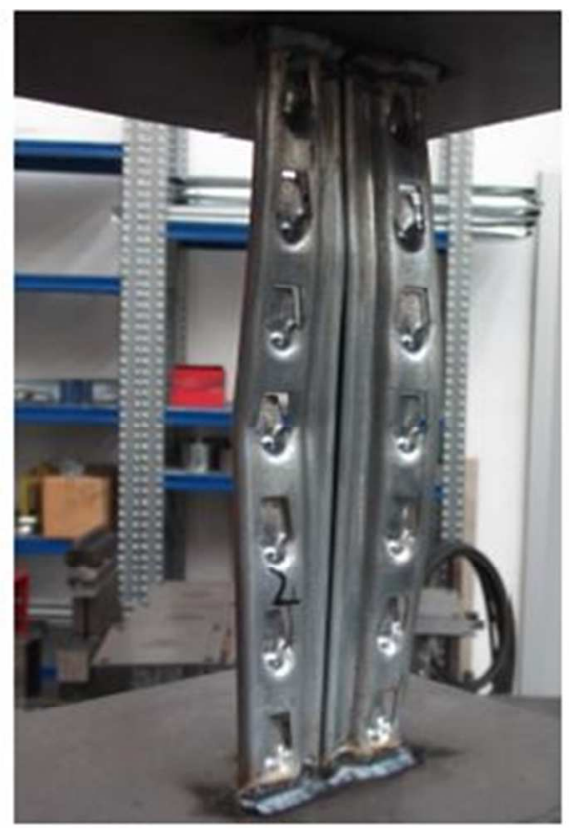

b)

Figure 3. Stub column test, a) EN15512 b) test on F1 specimen. $47 \times 30 \mathrm{~mm}(300 \times 300 \mathrm{DPI})$ 


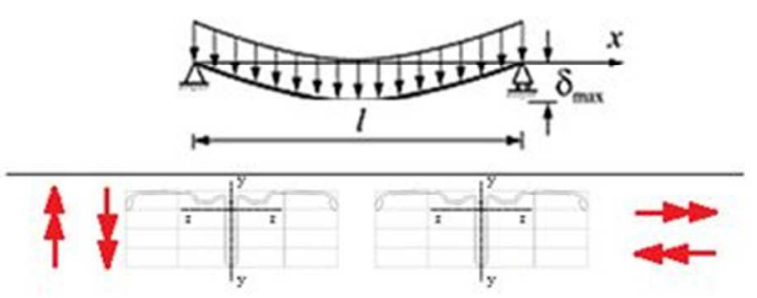

a)
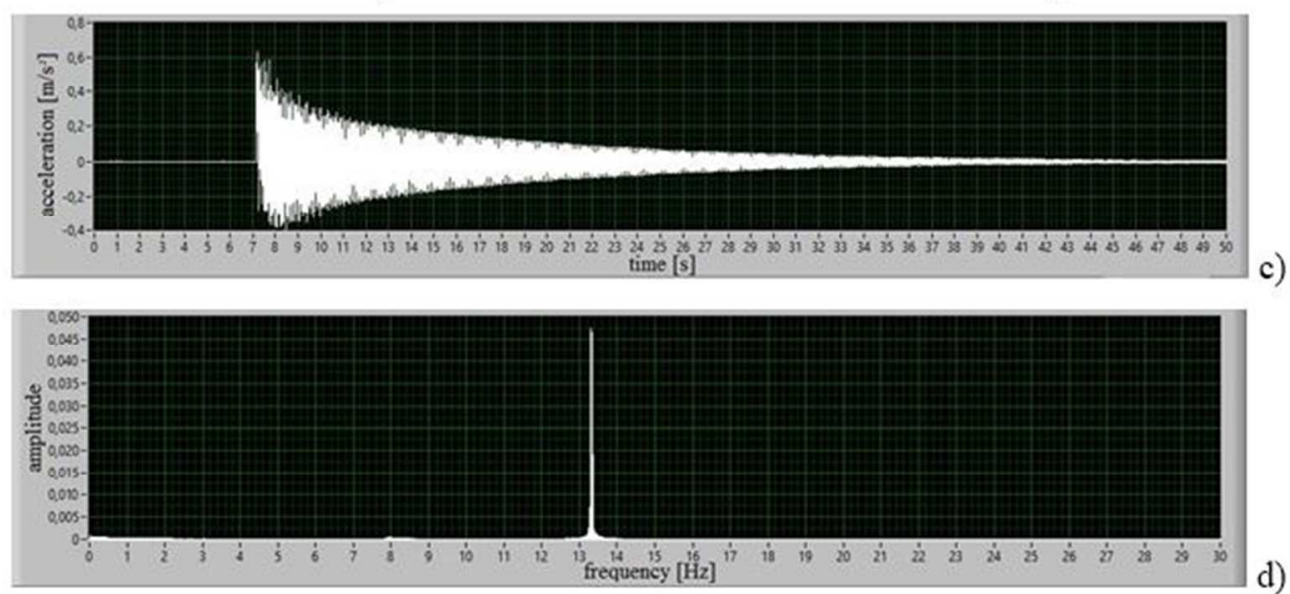

d)

Figure 4. Vibration test on upright: (a) the MEMS accelerometer, (b) test scheme, (c) the response in term of acceleration and $(\mathrm{d})$ the associated Fourier transform. $54 \times 43 \mathrm{~mm}(300 \times 300 \mathrm{DPI})$ 


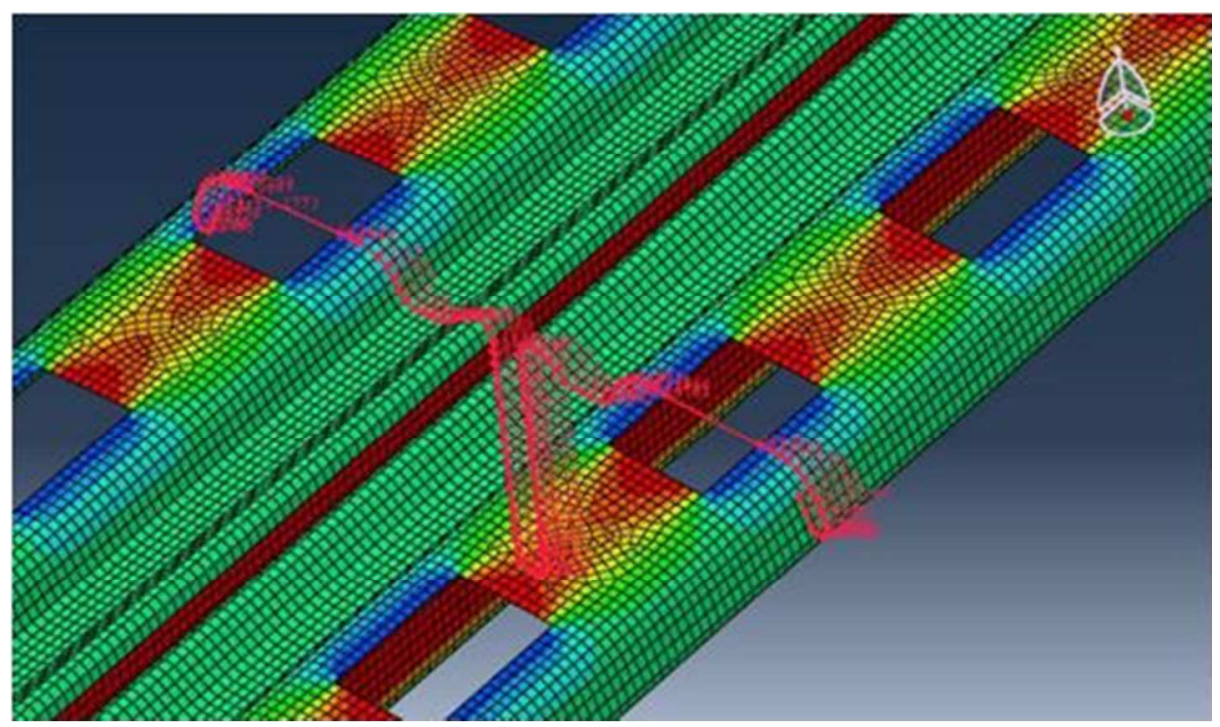

Figure 5. Details of the finite element model of perforated upright. $39 \times 23 \mathrm{~mm}(300 \times 300 \mathrm{DPI})$ 


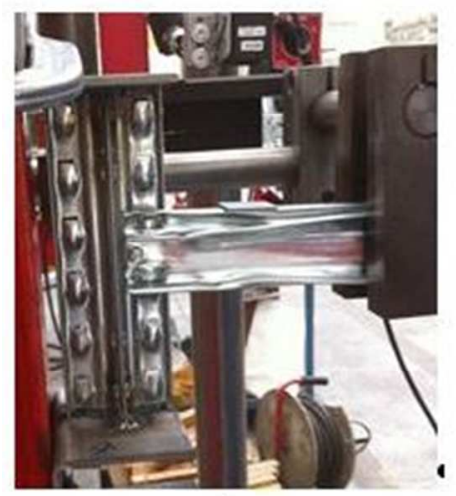

a)

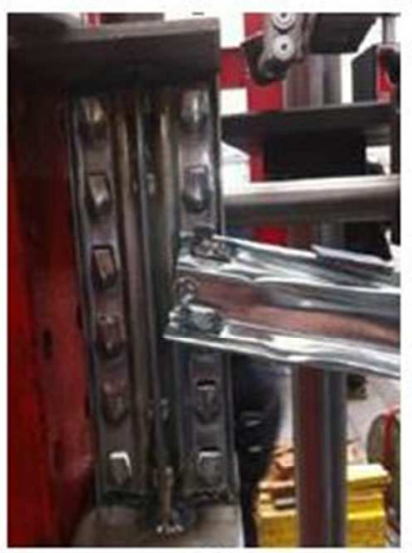

b)

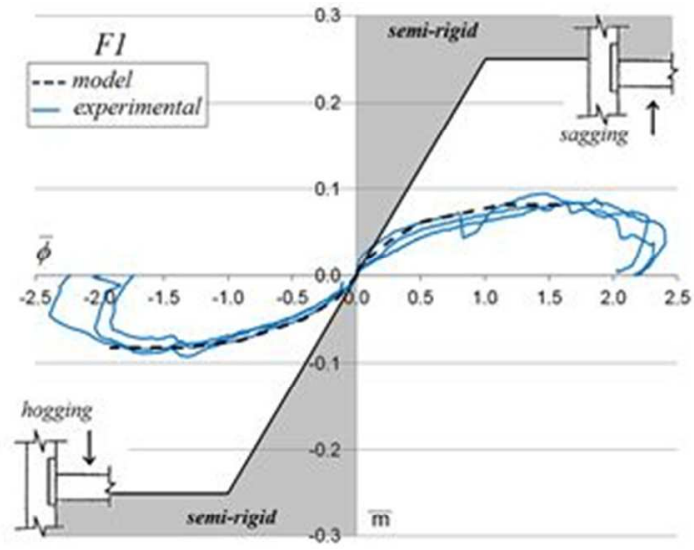

c)

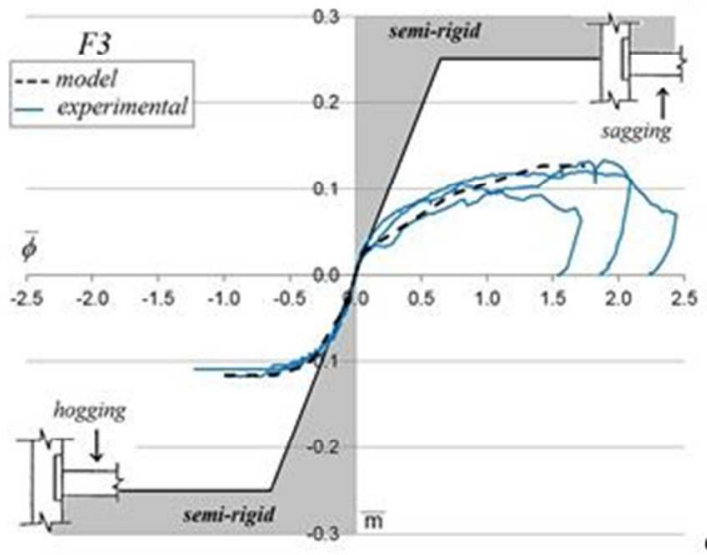

Figure 6. Beam to column joint experimental test: example of specimen $(a, b)$ and curves associated with F1 (c) and F3 (d) specimens. $48 \times 43 \mathrm{~mm}(300 \times 300 \mathrm{DPI})$ 


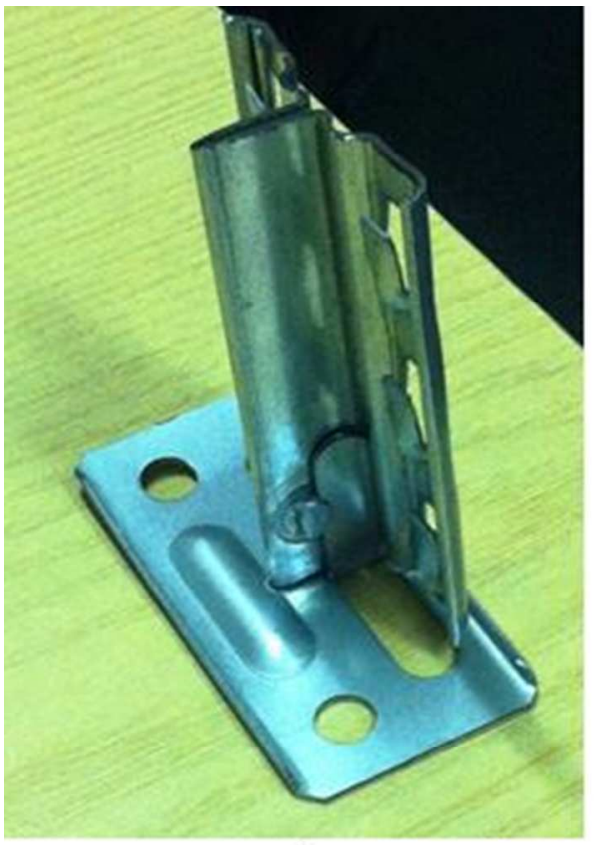

a)

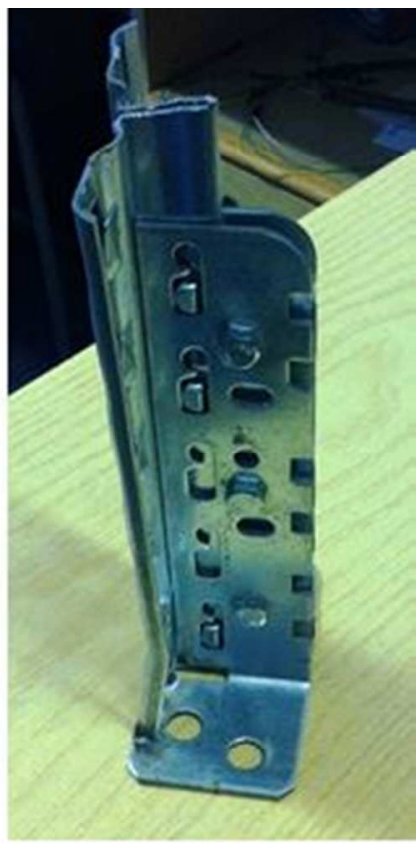

b)

Figure 7. The support (a) and the fixed (b) restraints base-plate connections. $39 \times 28 \mathrm{~mm}(300 \times 300 \mathrm{DPI})$ 


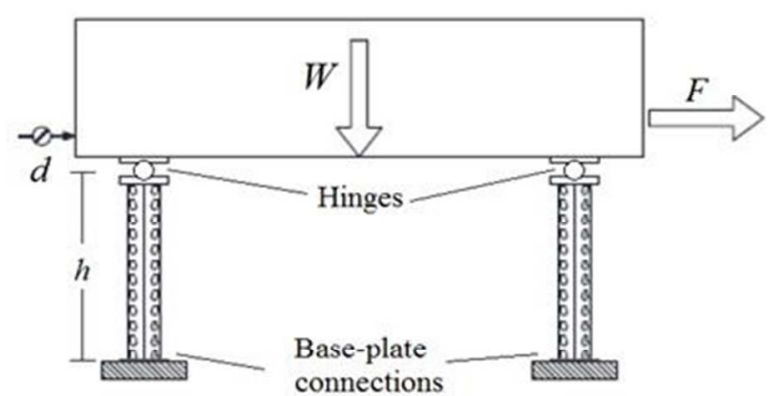

a)

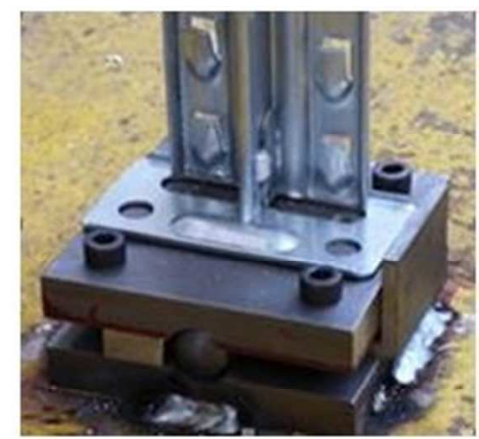

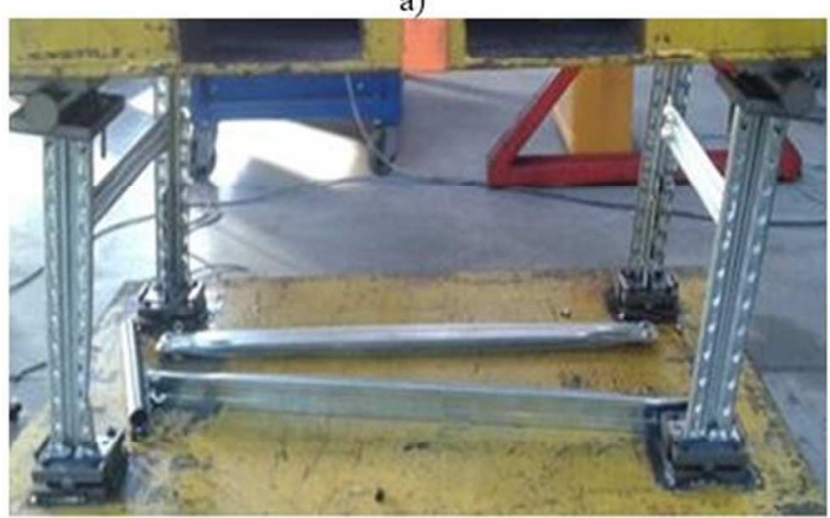

b)

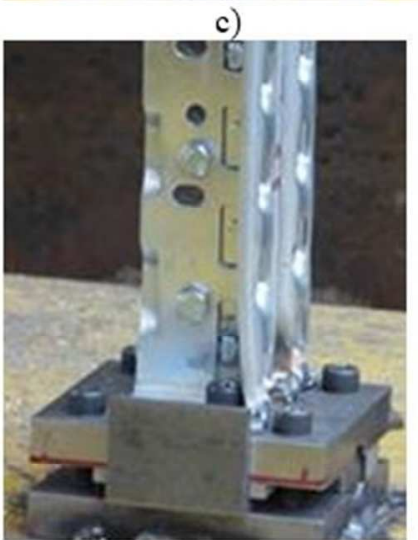

d)

Figure 8. Base-plate connection tests: scheme of the test (a), details of the specimen after test (b) and the $\mathrm{S}$ - and F-restraint bases. $56 \times 44 \mathrm{~mm}(300 \times 300 \mathrm{DPI})$ 


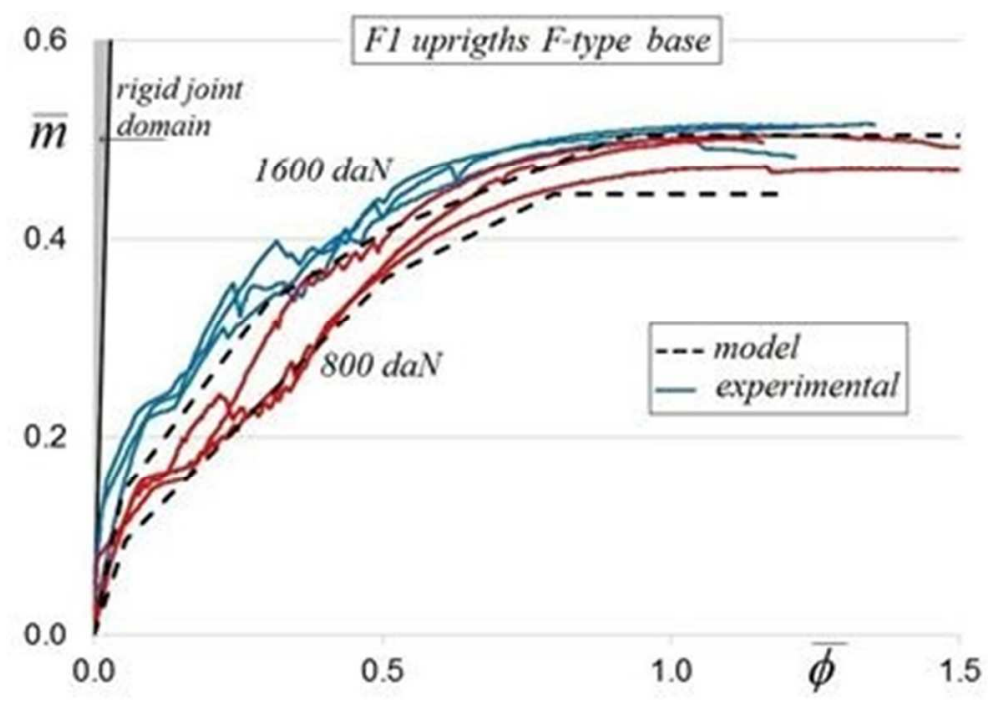

a)

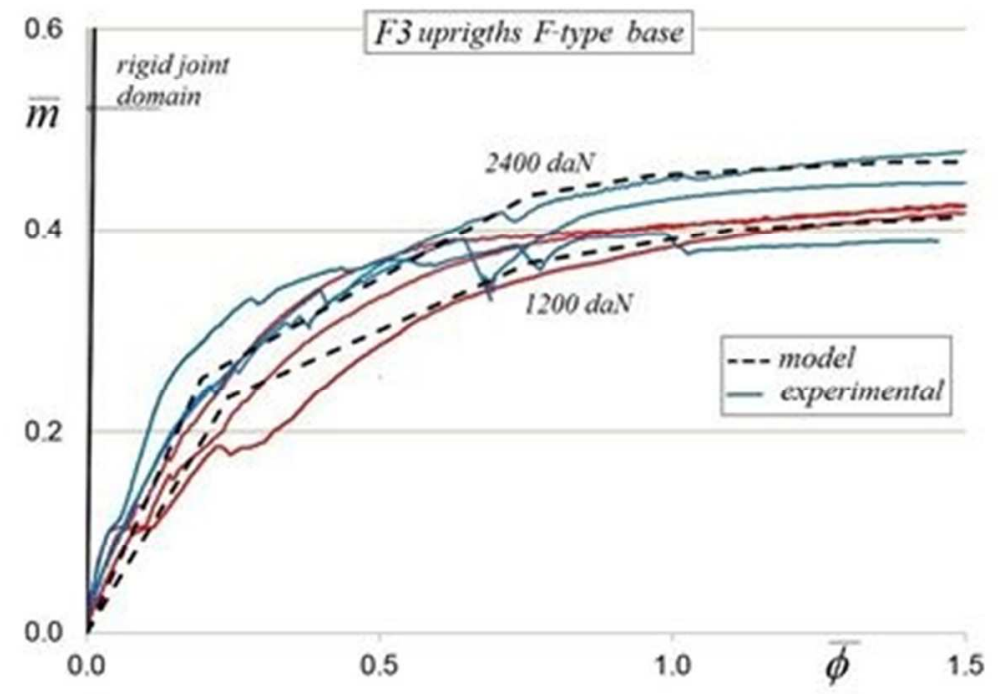

b)

Figure 9. Base-plate experimental test: curves associated with F1 (a) and F3 (b) joints. $109 \times 141 \mathrm{~mm}(96 \times 96 \mathrm{DPI})$

URL: http:/mc.manuscriptcentral.com/ueqe Email: bgencturk@uh.edu 


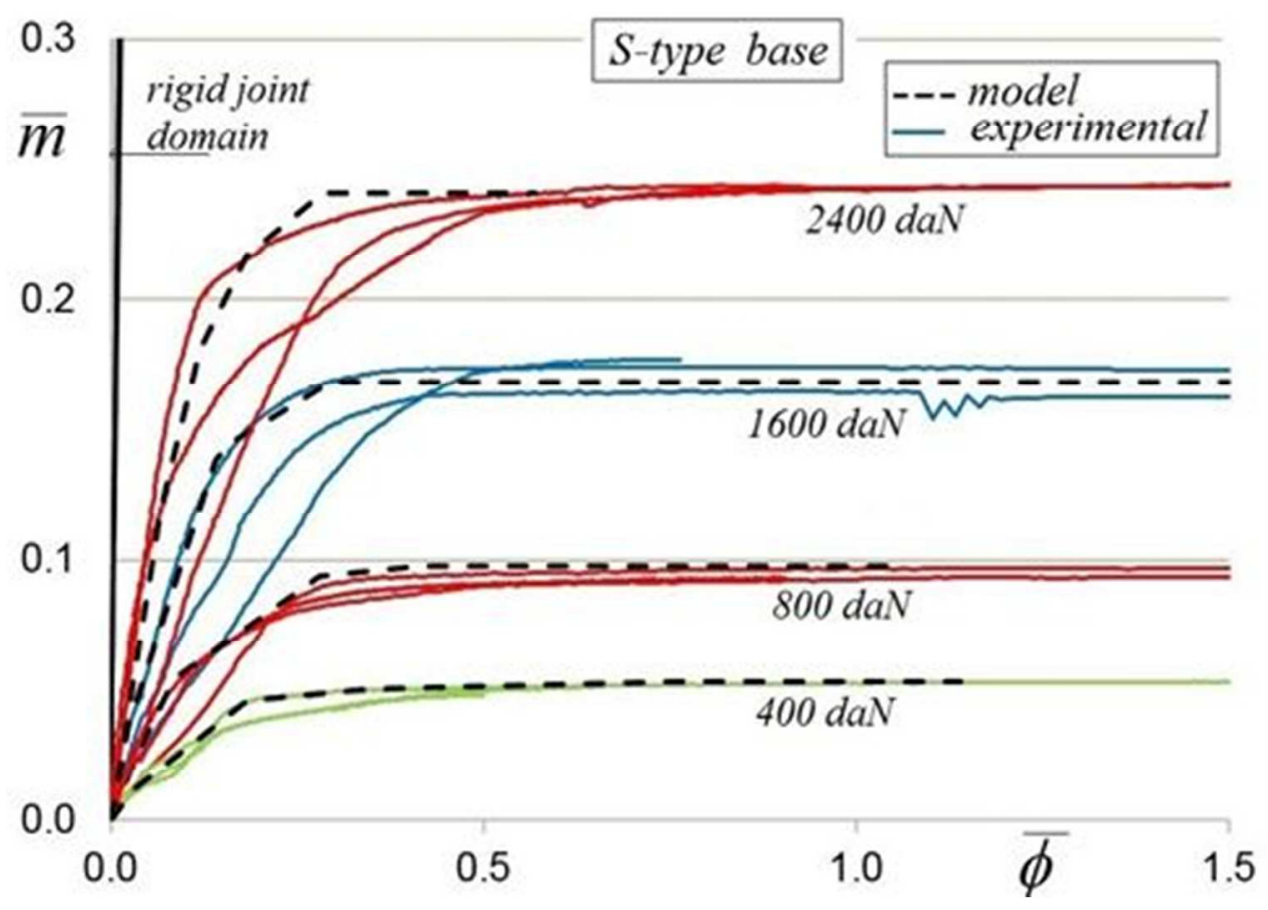

Figure 10. Base-plate experimental test: curves associated with S- type base plate. $40 \times 29 \mathrm{~mm}(300 \times 300 \mathrm{DPI})$

URL: http:/mc.manuscriptcentral.com/ueqe Email: bgencturk@uh.edu 

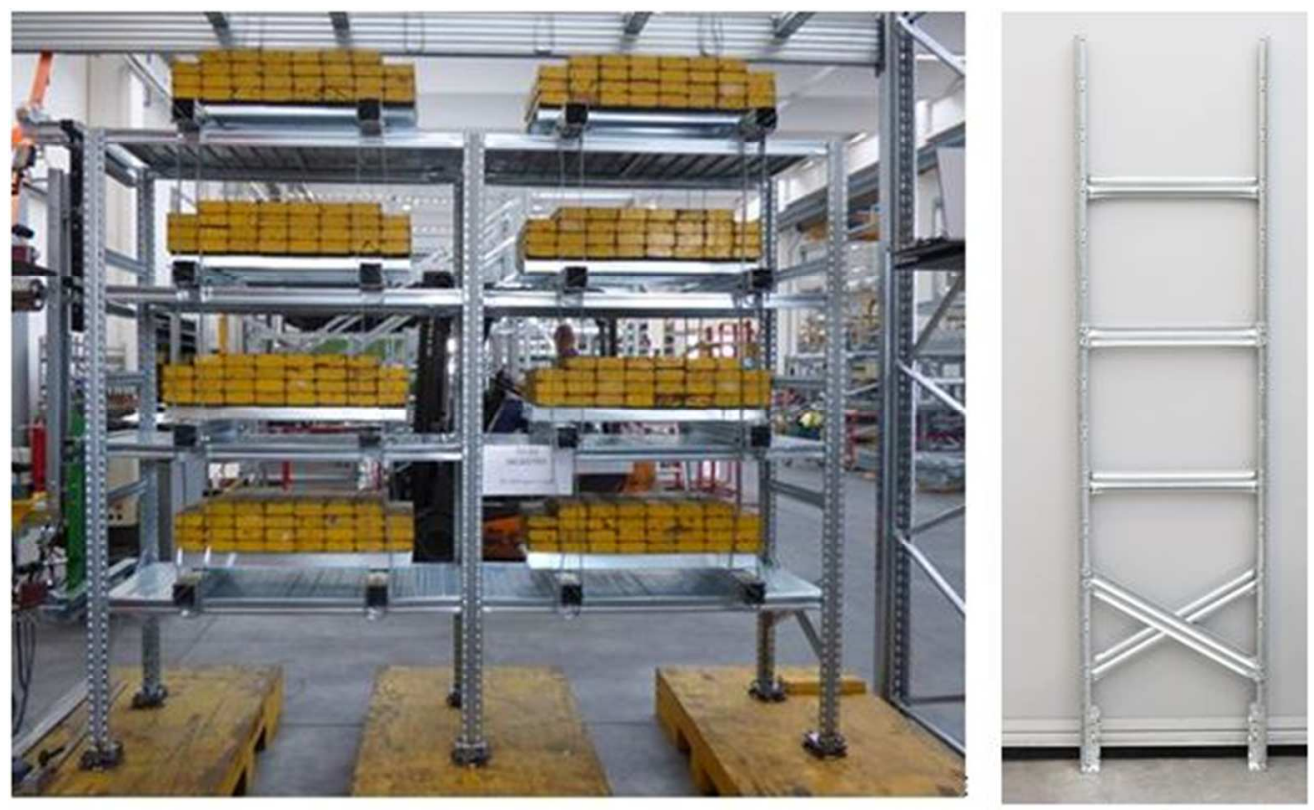

Figure 11 . The typical full-scale tested SR configuration. $52 \times 32 \mathrm{~mm}(300 \times 300$ DPI $)$ 


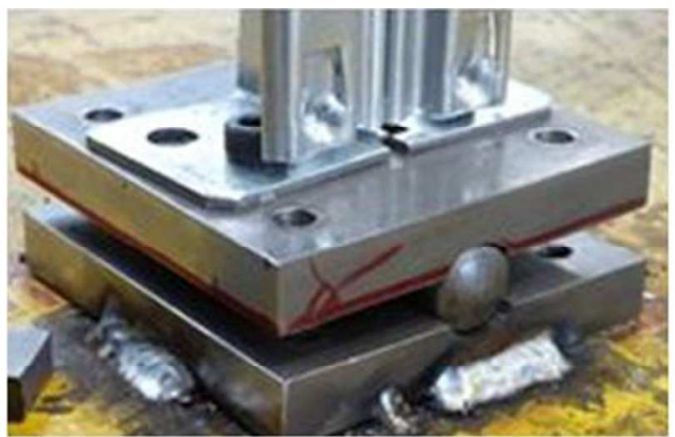

a)

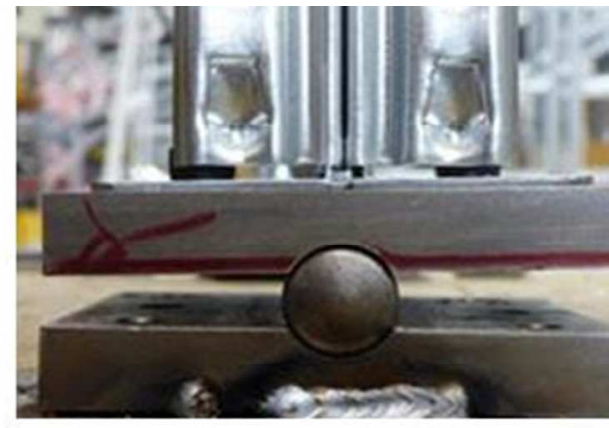

b)

Figure 12 . Details of the hinged base restraint $55 \times 20 \mathrm{~mm}(300 \times 300$ DPI $)$ 

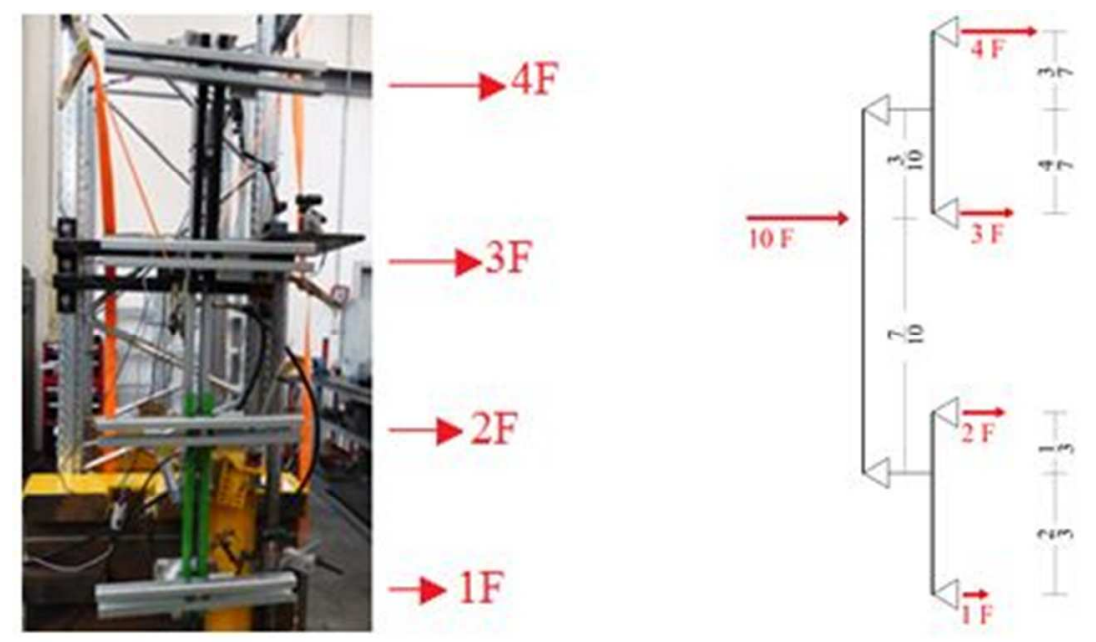

Figure 13. Load balance testing equipment to apply an inverse triangular pattern of forces. $35 \times 21 \mathrm{~mm}(300 \times 300 \mathrm{DPI})$ 

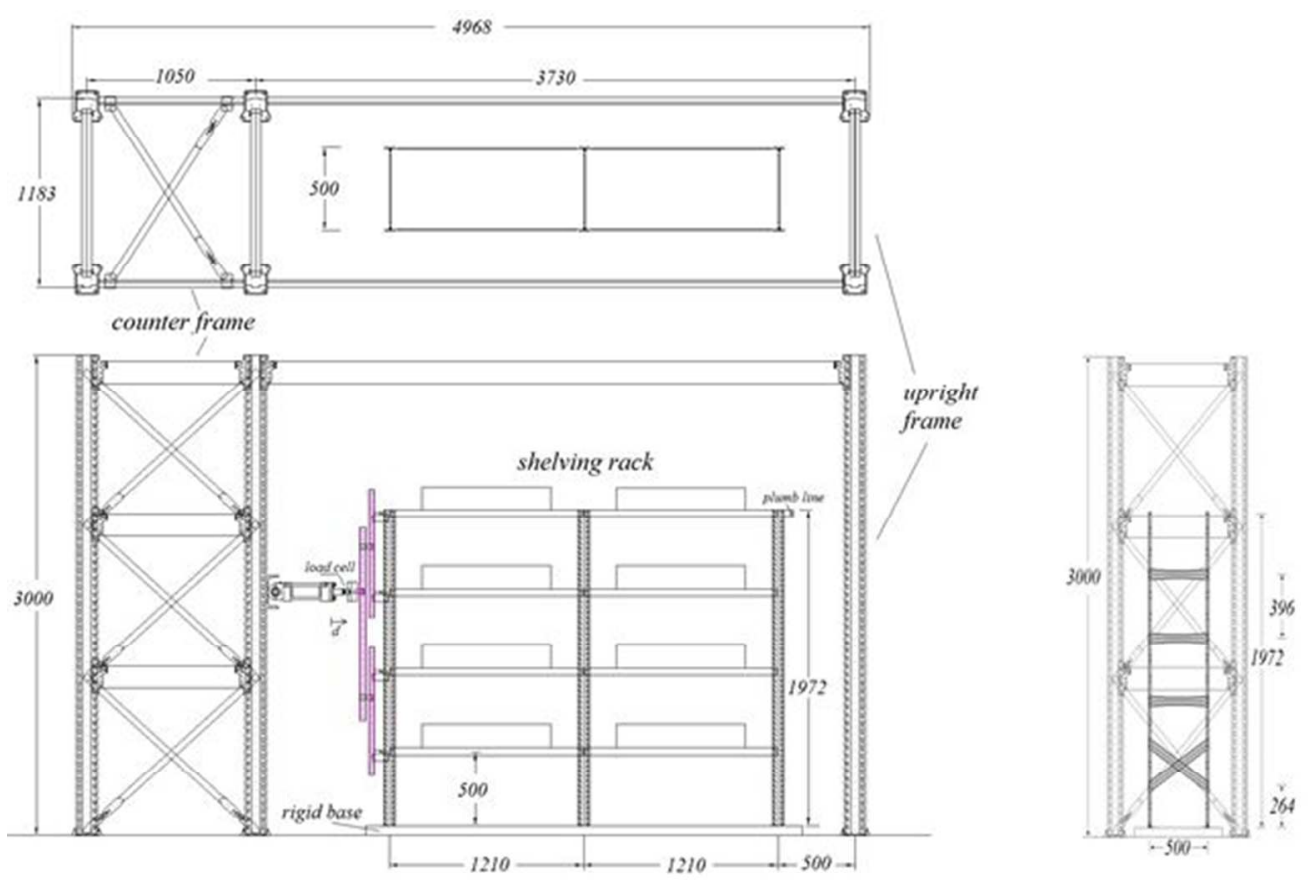

Figure 14. The specimen and the counter frame for the pushover tests. $54 \times 36 \mathrm{~mm}(300 \times 300 \mathrm{DPI})$ 


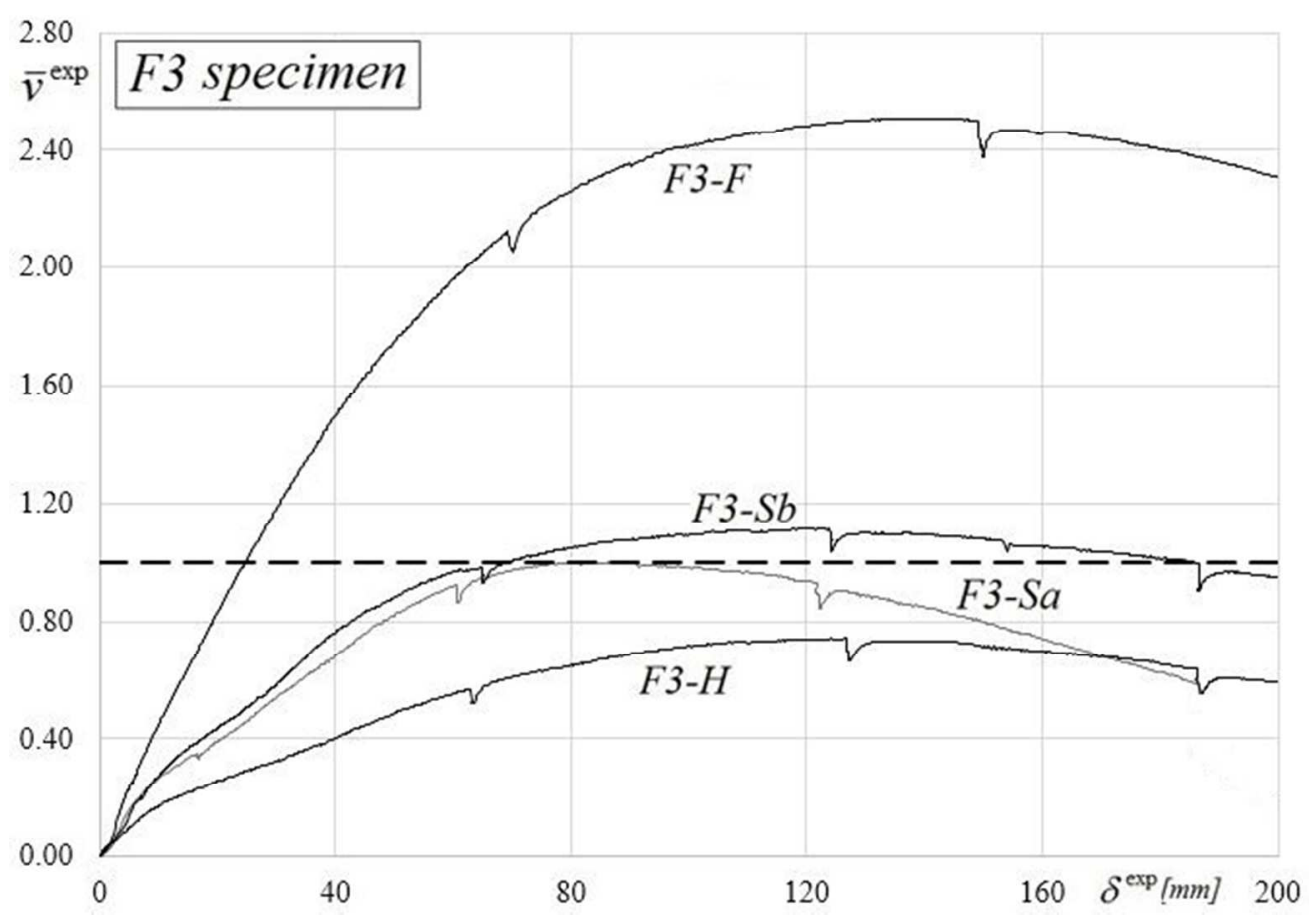

Figure 15. Pushover experimental curves on F1 specimens. $56 \times 39 \mathrm{~mm}(300 \times 300$ DPI $)$

URL: http:/mc.manuscriptcentral.com/ueqe Email: bgencturk@uh.edu 


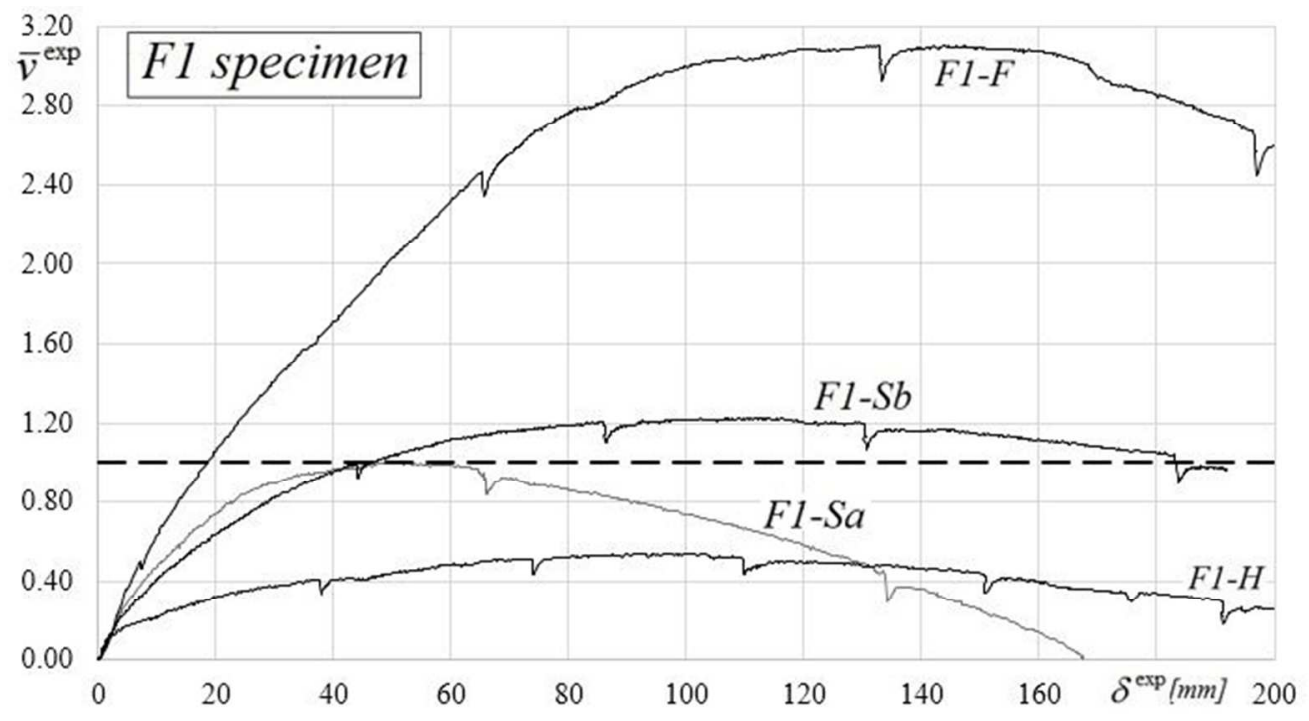

Figure 16. Pushover experimental curves on F3 specimens. $59 \times 32 \mathrm{~mm}(300 \times 300 \mathrm{DPI})$ 
Figure 17. Direct comparison between $\mathrm{F} 1$ and $\mathrm{F} 3$ specimens with hinged and fixed upright bases. $59 \times 33 \mathrm{~mm}(300 \times 300 \mathrm{DPI})$ 

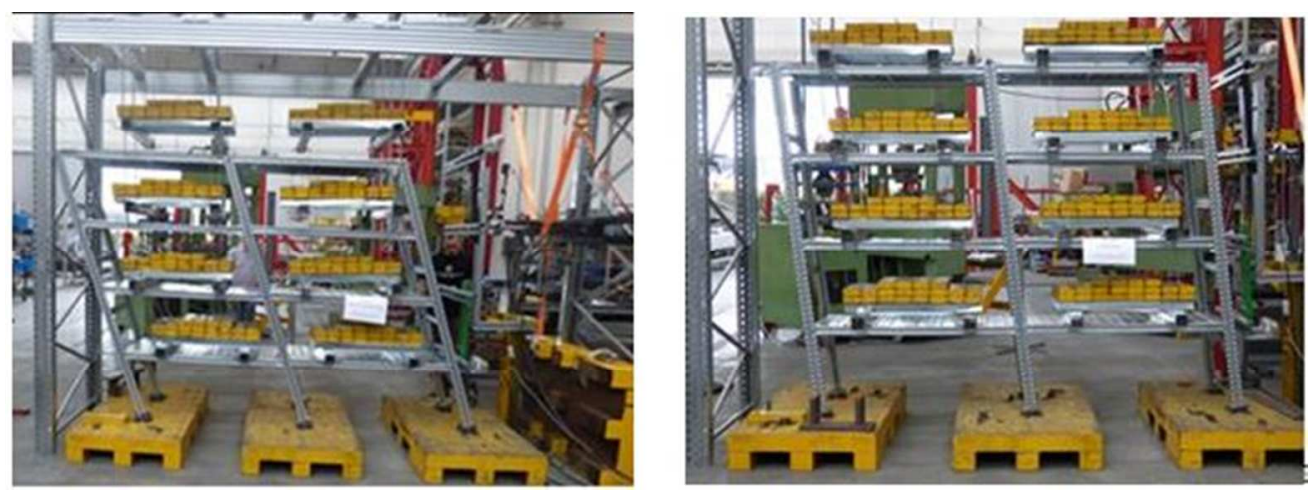

Figure 18. Large deformation on the specimen under testing. $55 \times 20 \mathrm{~mm}(300 \times 300 \mathrm{DPI})$ 

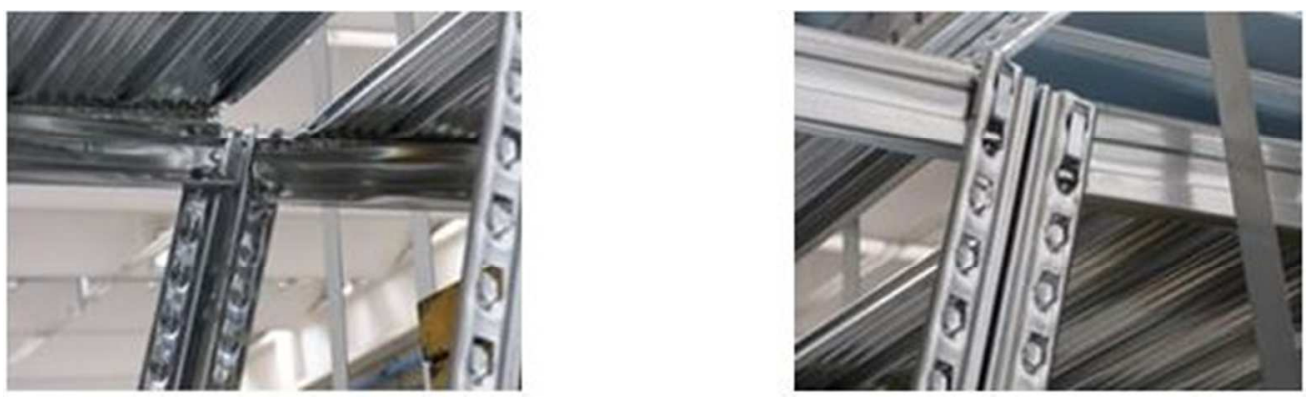

Figure 19. Details of the beam-to-column joints after tests $47 \times 14 \mathrm{~mm}(300 \times 300 \mathrm{DPI})$ 


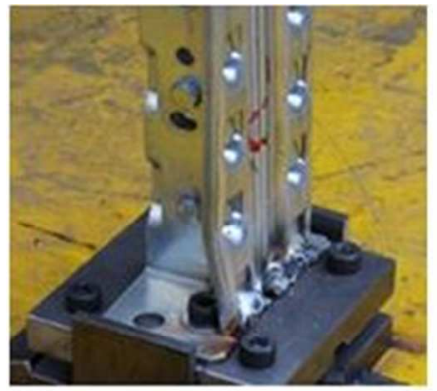

a)

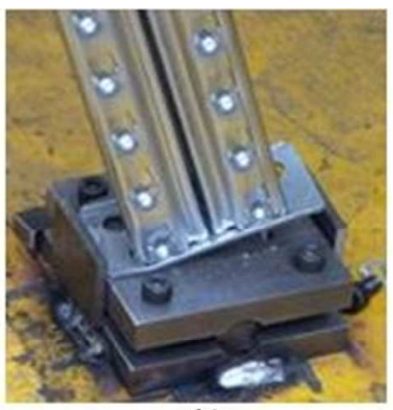

b)

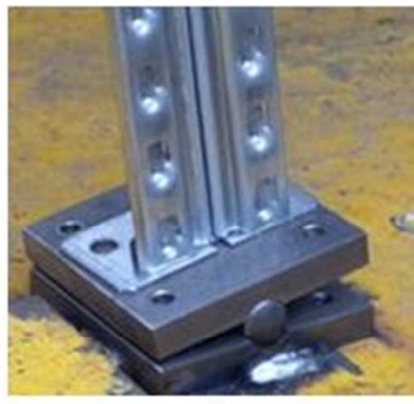

c)

Figure 20. Base-plate connection after the test: the typical deformed shape of the F-(a), S-(b) and $\mathrm{H}-(\mathrm{c})$ restraints $51 \times 17 \mathrm{~mm}(300 \times 300 \mathrm{DPI})$ 

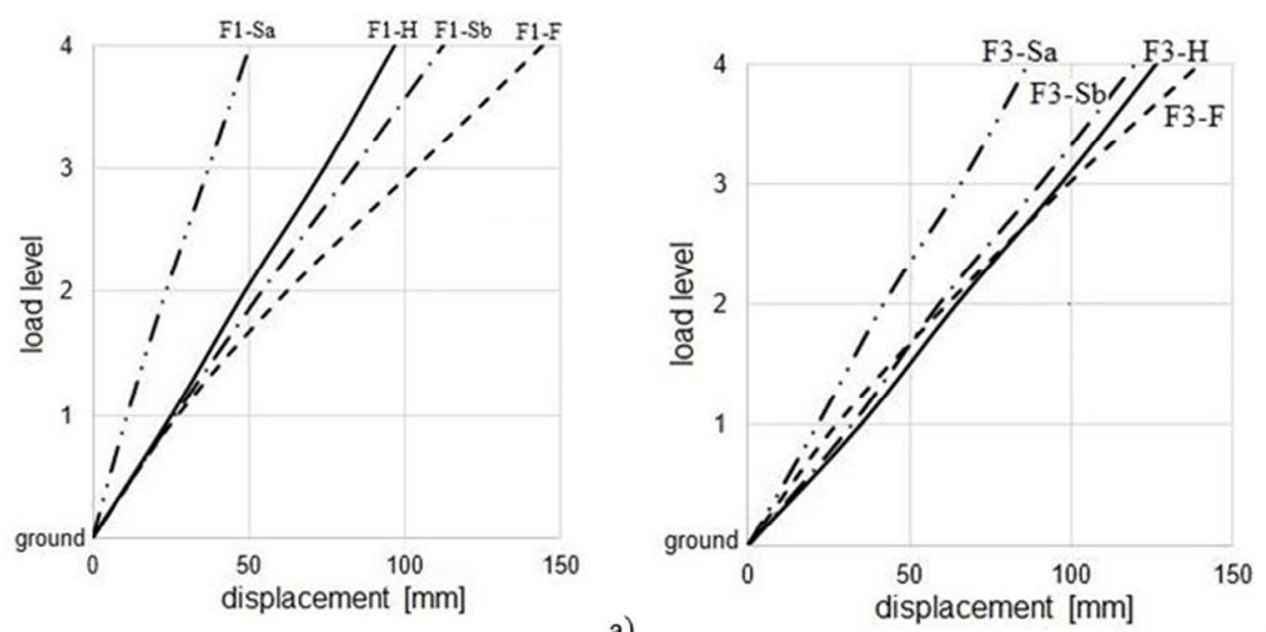

a)

b)

Figure 21. Displacements along elevation for (a) F1 and (b) F3 specimens. $59 \times 29 \mathrm{~mm}(300 \times 300$ DPI $)$ 


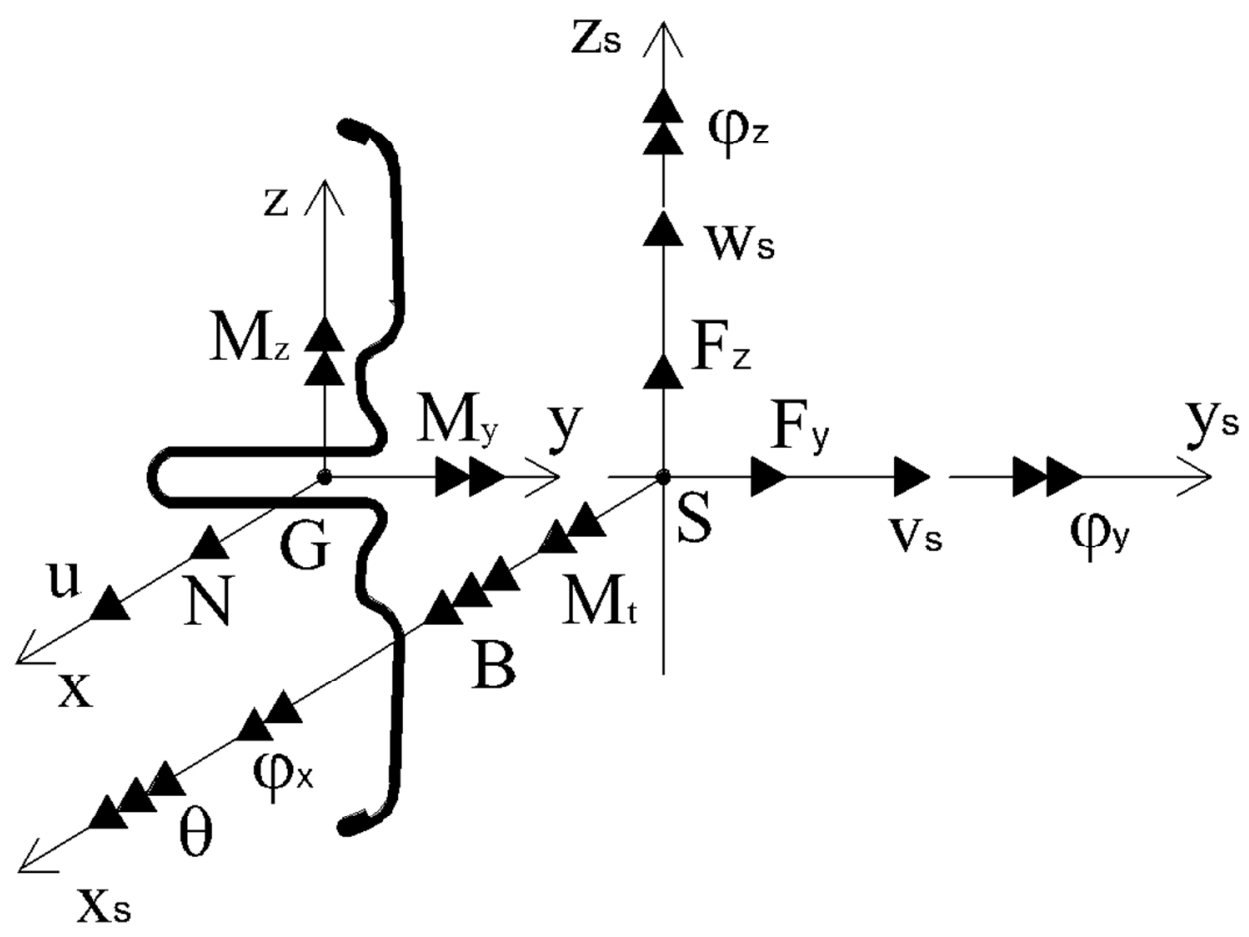

Figure 22. Sets of displacements and generalized forces at the node location for FE beam formulations with 7DOFs. $94 \times 68 \mathrm{~mm}(300 \times 300$ DPI) 


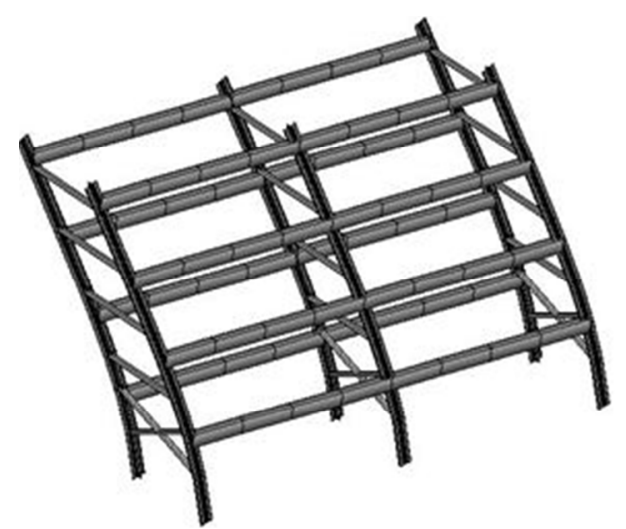

a)

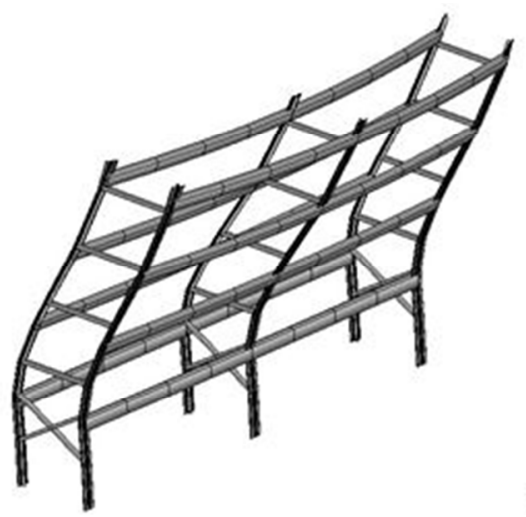

b)

Figure 23. Example of the 1st (a) and 2 nd (b) mode shape obtained by Śiva software. $53 \times 21 \mathrm{~mm}(300 \times 300 \mathrm{DPI})$ 

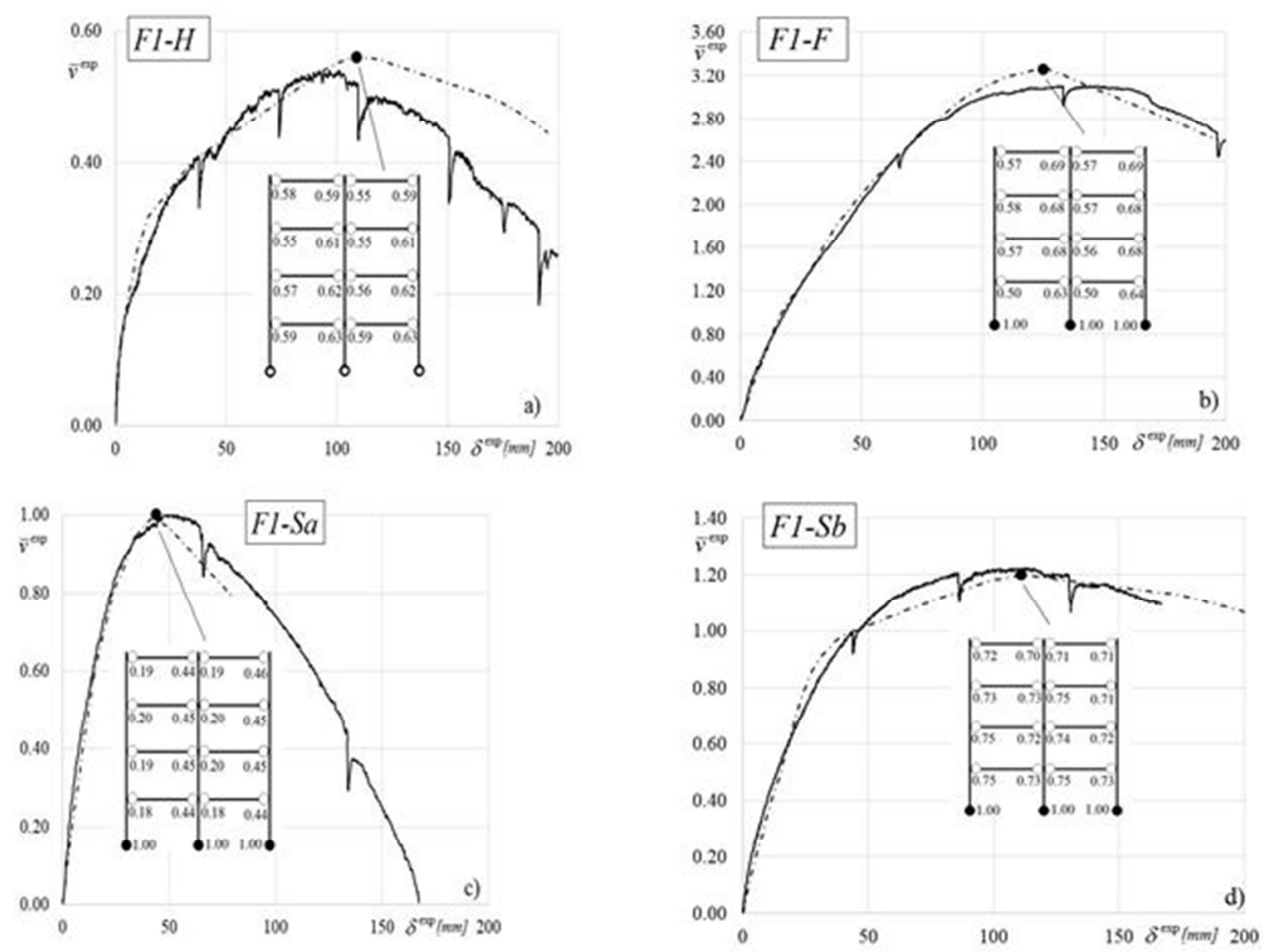

Figure 24. Experimental-versus numerical pushover curves for the F1-SRs. $53 \times 40 \mathrm{~mm}(300 \times 300 \mathrm{DPI})$

URL: http:/mc.manuscriptcentral.com/ueqe Email: bgencturk@uh.edu 

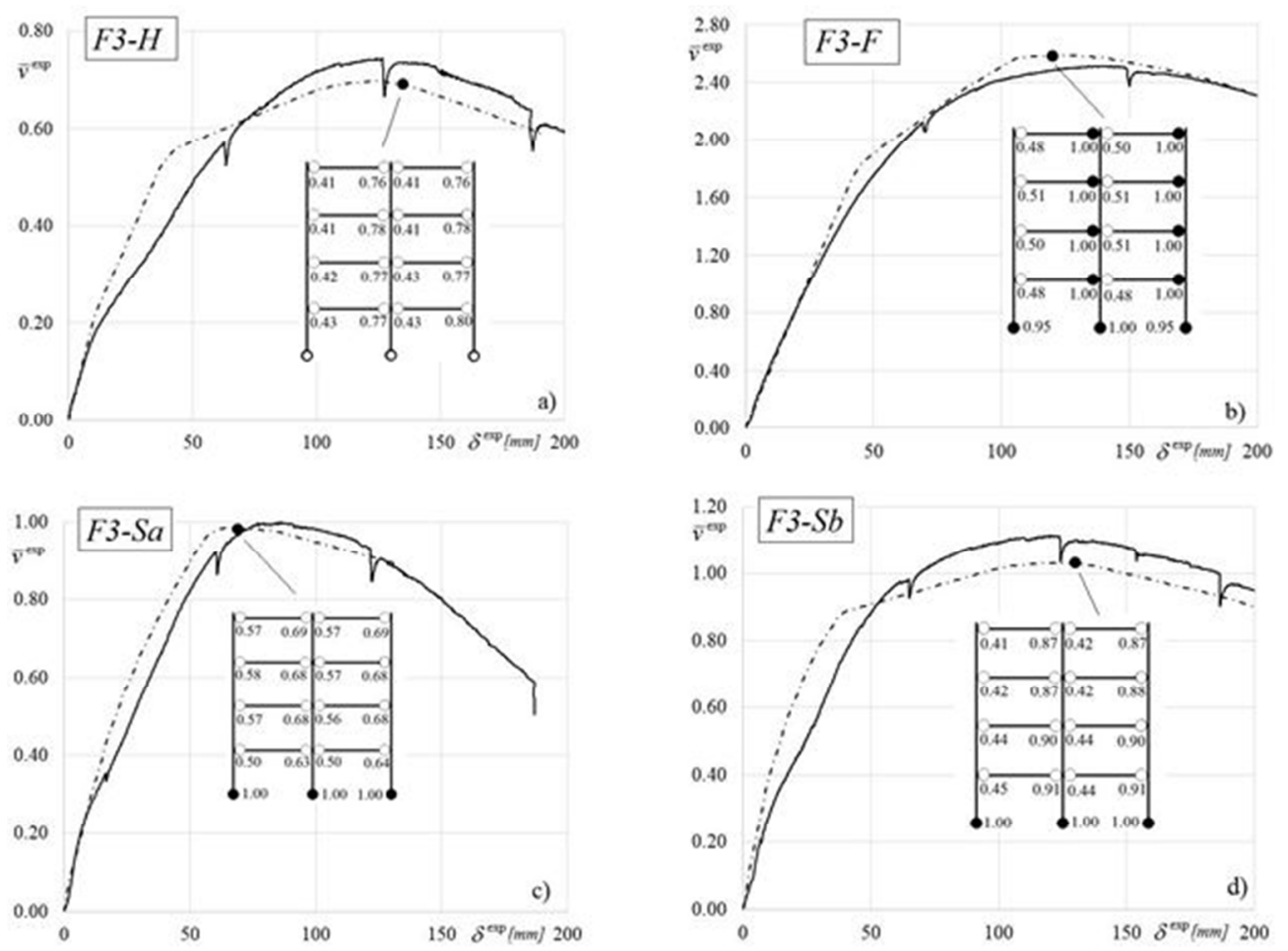

Figure 25. Experimental-versus numerical pushover curves for the F3-SRs. $53 \times 39 \mathrm{~mm}(300 \times 300 \mathrm{DPI})$

URL: http:/mc.manuscriptcentral.com/ueqe Email: bgencturk@uh.edu 
Table 1. Gross cross-section properties of the considered uprights.

\begin{tabular}{|c|c|c|}
\hline Link_tabla & F1 & F3 \\
\hline$A_{g} / A_{\text {perf }}$ & 1.10 & 1.09 \\
\hline$I_{y} / I_{z}$ & 6.69 & 6.61 \\
\hline$I_{t}\left[\mathrm{~mm}^{4}\right]$ & 42.12 & 245.62 \\
\hline$I_{w}\left[\mathrm{~mm}^{6}\right]$ & $0.49 \cdot 10^{6}$ & $0.89 \cdot 10^{6}$ \\
\hline$y_{s} / t$ & 2.35 & 1.38 \\
\hline
\end{tabular}

Link_tab1b 
Table 2. Results from free vibrational test.

1

2

3

4

5

6

7

8

9

10

11

12

13

14

15

16

17

18

19

20

21

22

23

24

25

26

27

28

29

30

31

32

33

34

35

36

37

38

39

40

41

42

43

44

45

46

47

48

49

50

51

52

53

54

55

56

57

58

59

60

\begin{tabular}{|c|c|c|}
\hline Upright & Axes & Frequency [Hz] \\
\hline \multirow{2}{*}{ F1 } & y-y & 27.3 \\
\cline { 2 - 3 } & z-z & 12.5 \\
\hline \multirow{2}{*}{ F3 } & $y-y$ & 29.7 \\
\cline { 2 - 3 } & z-z & 13.1 \\
\hline
\end{tabular}


Table 3. Influence of perforations on the uprights.

\begin{tabular}{|c|c|c|c|c|c|c|c|}
\cline { 3 - 8 } \multicolumn{2}{c|}{} & \multicolumn{3}{c|}{ F1_upright } & \multicolumn{3}{c|}{ F3_upright } \\
\cline { 3 - 8 } \multicolumn{2}{c|}{} & $\exp$ & num & $\exp /$ num & $\exp$ & num & exp/num \\
\hline Area & $Q^{N}$ & 0.63 & 0.66 & 0.954 & 0.79 & 0.81 & 0.975 \\
\hline \multirow{2}{*}{$\begin{array}{c}\text { Second moment } \\
\text { of Area }\end{array}$} & $I_{y, \text { eff }} / I_{y}$ & 0.88 & 0.89 & 0.989 & 0.91 & 0.92 & 0.989 \\
\cline { 2 - 9 } & $I_{z, \text { eff }} / I_{z}$ & 0.67 & 0.74 & 0.905 & 0.68 & 0.75 & 0.907 \\
\hline
\end{tabular}


Table 4. Key features of the full-scale specimens

1

2

3

4

5

6

7

8

9

10

11

12

13

14

15

16

17

18

19

20

21

22

23

24

25

26

27

28

29

30

31

32

33

34

35

36

37

38

39

40

41

42

43

44

45

46

47

48

49

50

51

52

53

54

55

56

57

58

59

60

\begin{tabular}{|c|c|c|c|c|c|c|c|c|c|c|}
\hline \multirow{2}{*}{ Name } & \multicolumn{2}{|c|}{ Components } & \multicolumn{3}{|c|}{ Base restraint } & \multicolumn{3}{c|}{$\begin{array}{c}\text { Masses } \\
{[\mathrm{kg}]}\end{array}$} & \multicolumn{2}{c|}{$\begin{array}{c}\text { Out-of-plumb } \\
\text { angle [mrad] }\end{array}$} \\
\cline { 2 - 11 } & $F 1$ & $F 3$ & Hinge & Fixed & Support & 100 & 200 & 300 & Imp_D & Imp_C \\
\hline F1-H & $X$ & & $X$ & & & $X$ & & & 2.22 & 2.22 \\
\hline F1-F & $X$ & & & $X$ & & & $X$ & & 2.67 & 2.67 \\
\hline F1-Sa & $X$ & & & & $X$ & & $X$ & & 5.55 & 5.55 \\
\hline F1-Sb & $X$ & & & & $X$ & $X$ & & & 1.11 & 6.67 \\
\hline F3-H & & $X$ & $X$ & & & & $X$ & & 5.55 & 5.55 \\
\hline F3-F & & $X$ & & $X$ & & & & $X$ & 5.55 & 1.67 \\
\hline F3-Sa & & $X$ & & & $X$ & & & $X$ & 5.55 & 2.67 \\
\hline F3-Sb & & $X$ & & & $X$ & & $X$ & & 5.55 & 5.55 \\
\hline
\end{tabular}


Table 5. Values of the fundamental period of vibrations, expressed in seconds

1

2

3

4

5

6

7

8

9

10

11

12

13

14

15

16

17

18

19

20

21

22

23

24

25

26

27

28

29

30

31

32

33

34

35

36

37

38

39

40

41

42

43

44

45

46

47

48

49

50

51

52

53

54

55

56

57

58

59

60

\begin{tabular}{|c|c|c|c|c|c|c|c|c|}
\hline \multirow{2}{*}{$\mathrm{T}_{1}[s]$} & \multicolumn{4}{|c|}{$F 1$ _specimens } & \multicolumn{4}{c|}{$F 3$ specimens } \\
\cline { 2 - 9 } & $H$ & $F$ & $S a$ & $S b$ & $H$ & $F$ & $S a$ & $S b$ \\
\hline Unloaded & 0.179 & 0.126 & 0.152 & 0.163 & 0.174 & 0.113 & 0.128 & 0.131 \\
\hline Loaded & 1.232 & 1.274 & 1.442 & 1.114 & 1.237 & 1.015 & 1.051 & 0.938 \\
\hline
\end{tabular}


Table 6. Key data of the deformed shape in correspondence of the maximum lateral load

\begin{tabular}{|c|c|c|c|c|c|c|}
\cline { 2 - 7 } \multicolumn{1}{c|}{} & $\bar{v}_{\max }^{\exp }$ & $\begin{array}{c}\delta_{\max }^{\exp } \\
{[\mathrm{mm}]}\end{array}$ & $\begin{array}{c}\Delta_{1} / h_{1} \\
{[\%]}\end{array}$ & $\begin{array}{c}\Delta_{2} / h_{2} \\
{[\%]}\end{array}$ & $\begin{array}{c}\Delta_{3} / h_{3} \\
{[\%]}\end{array}$ & $\begin{array}{c}\Delta_{4} / h_{4} \\
{[\%]}\end{array}$ \\
\hline F1-H & 0.54 & 96.70 & 5.12 & 4.74 & 5.12 & 4.55 \\
\hline F1-F & 3.11 & 143.99 & 5.53 & 7.05 & 8.31 & 8.21 \\
\hline F1-Sa & 1.00 & 50.64 & 2.25 & 2.52 & 2.77 & 2.69 \\
\hline F1-Sb & 1.22 & 112.47 & 5.34 & 5.62 & 5.95 & 5.81 \\
\hline F3-H & 0.75 & 126.63 & 7.04 & 6.01 & 6.54 & 5.98 \\
\hline F3-F & 2.51 & 139.83 & 5.49 & 6.94 & 7.57 & 8.25 \\
\hline F3-Sa & 1.00 & 86.41 & 4.32 & 4.12 & 4.83 & 4.20 \\
\hline F3-Sb & 1.12 & 120.14 & 6.50 & 5.46 & 6.37 & 5.95 \\
\hline
\end{tabular}


Table 7. Prediction of the dynamic SR properties.

\begin{tabular}{|c|c|c|c|}
\cline { 2 - 4 } \multicolumn{1}{c|}{} & unloaded & \multicolumn{2}{c|}{ loaded } \\
\cline { 2 - 4 } \multicolumn{1}{c|}{} & $T_{1}^{\text {exp }} / T_{1}^{\text {Siva }}$ & $T_{1}^{\text {exp }} / T_{1}^{\text {Siva }}$ & $m p[\%]$ \\
\hline F1-H & 1.122 & 1.152 & 80.81 \\
\hline F1-F & 1.154 & 1.121 & 74.81 \\
\hline F1-Sa & 1.212 & 1.112 & 77.62 \\
\hline F1-Sb & 1.225 & 1.111 & 79.51 \\
\hline F3-H & 1.124 & 1.258 & 84.78 \\
\hline F3-F & 1.025 & 1.251 & 78.56 \\
\hline F3-Sa & 1.051 & 1.213 & 79.26 \\
\hline F3-Sb & 1.238 & 1.111 & 80.80 \\
\hline
\end{tabular}


Table 8. Key data related to the accuracy of the 7DOFs FE simulations. 